\title{
Knowledge, Attitudes, and Practice Patterns of Health Professionals Toward Medical and Non-medical Stimulant Use by Young Adults
}

\author{
Natalia Y. Loskutova, MD, PhD, Jason Waterman, DO, Elisabeth Callen, PhD, GStat, \\ Elizabeth W. Staton, MSTC, Emily Bullard, MPH, and Joel Shields, MA
}

Background: The role of family physicians (FPs) and college health professionals (CHPs) in stimulant treatment and nonmedical use of stimulants is not clear.

Objective: To investigate the current practices, concerns, needs, beliefs, barriers, and facilitators to appropriate pharmacological treatment of teens and young adults with attention deficit hyperactivity disorder (ADHD) and prevention of nonmedical use and diversion.

Methods: A cross-sectional survey developed by the project team and experts in the field, delivered to national sample of FPs and CHPs.

Results: A total of 794 completed surveys were analyzed. The average age of respondents was $51.6 \pm$ 10.3 years; $50.6 \%$ of the respondents were female. The majority of $\mathrm{CHPs}(\mathbf{8 0 . 6 \%})$ reported they spend $75 \%$ to $100 \%$ of their time with patients age 17 to 24 years and $74.0 \%$ of FPs reported they spend less than $25 \%$ of their time with this age group. The majority $(91.7 \%)$ of the respondents indicated that untreated ADHD affects quality of life, and $76.4 \%$ indicated untreated ADHD is often associated with risky behaviors. More CHPs than FPs always refer out for ADHD diagnosis $(70.7 \%$ vs $52.1 \% ; \boldsymbol{P}<.001)$. Most respondents $(81.2 \%)$ were concerned with ADHD medication diversion, and $84.2 \%$ believed that diversion or abuse is a problem overall. Respondents indicated they are unprepared to provide patient education on decisions about pharmacotherapy or behavioral therapy choices for adult ADHD.

Conclusion: There is an opportunity to enhance safety and effectiveness of ADHD management in young adults. Additional resources and interventions are needed to improve medication management, reduce misuse, and ensure safe and appropriate use of stimulants. ( $\mathrm{J}$ Am Board Fam Med 2020;33: 59-70.)

Keywords: Adolescent, Attention Deficit Hyperactivity Disorder, Central Nervous System Stimulants, Cross-Sectional Studies, Family Physicians, Patient Safety, Quality of Life, Surveys and Questionnaires, Universities, Young Adult

Attention deficit hyperactivity disorder (ADHD) is a common neurodevelopmental disorder affecting about $3 \%$ to $10 \%$ of school-aged children and adolescents. ${ }^{1-3}$ Nearly half of the children and ad-

This article was externally peer reviewed.

Submitted 26 February 2019; revised 23 July 2019; accepted 23 July 2019.

From the American Academy of Family Physicians National Research Network, Leawood, KS (NL, EC, EB, JS); Heritage Health and Housing, Commack, NY (JW); University of Colorado Denver Department of Family Medicine, Aurora, CO (EWC).

Funding: This study was supported by Shire US, Inc., through the Coalition to Prevent ADHD Medication Misuse (CPAMM). Shire US, Inc. was not involved in the study design, data analysis and interpretation, or reporting of this work. olescents with $\mathrm{ADHD}$ continue to have symptoms of the disorder in adulthood. ${ }^{4,5}$ Stimulants are the most common medications prescribed for ADHD, and pharmacological treatment has shown a posi-

Conflict of interest: none declared.

The authors have full control of all primary data and that they agree to allow the journal to review their data if requested.

Ethical approval: All procedures performed in this study involving human participants were in accordance with the ethical standards of the institutional AAFP IRB and with the 1964 Helsinki declaration and its later amendments or comparable ethical standards.

Prior presentations: The findings reported in this work have not been previously published and that the manuscript is not being simultaneously submitted elsewhere. The preliminary results were previously presented as a poster at the 
tive impact on outcomes, long-term prognosis, and quality of life in children and adults with a diagnosis of ADHD. One important consideration related to stimulant medications is the appropriate use of these medications and their potential for abuse. Recent research has documented that the nonmedical use of prescription stimulants is a substantial and growing problem among young adults and college students. ${ }^{6-8}$ Nonmedical use of stimulants on college campuses is a well-documented problem. ${ }^{9,10}$ Physicians have been identified as the second most frequent source of the misused stimulants. ${ }^{11}$ It is important to understand the role the health care professionals play in treating ADHD in young adults, and their potential role in prevention of nonmedical use of stimulants.

Even though ADHD patients have stimulant medications prescribed by both primary care providers and providers in college health centers, there is very little research on commonalities and differences in the way the settings manage ADHD, prescribe and monitor medications, and prevent inappropriate use of stimulants.

The objective of this article is to present methodology and results of a provider survey on the current care practices, concerns, needs, beliefs, barriers, and facilitators to appropriate pharmacological treatment, and the prevention of nonmedical use of stimulants among teens and young adults age 17 to 26 years. The survey study intended to provide descriptive data on primary care providers and providers in college health centers and was not designed to test any specific a priori hypothesis.

\section{Methods}

\section{Study Overview}

This study was a cross-sectional survey of national samples of members of American Academy of Family Physicians (AAFP) and members of the American College Health Association (ACHA). The study was approved by the AAFP Institutional Review Board (IRB).

American College of Osteopathic Pediatricians (ACOP) Spring Conference, April 14-17, 2016, Phoenix, Arizona

Corresponding author: Natalia Y. Loskutova, MD, PhD, American Academy of Family Physicians National Research Network, 11400 Tomahawk Creek Pkwy, Leawood, KS 66211 (E-mail: nloskutova@hotmail.com).

\section{Sample and Setting}

The study was conducted with 1) a random sample of the AAFP nonretired members who reside in the United States, spend at least $50 \%$ of their time in direct patient care, and have responsibility for the care of teenagers and young adults $(n=2000$; AAFP members, family physicians [FPs]); and 2) the segment of ACHA college health professionals working in student health centers $(\mathrm{n}=573$; ACHA members, college health professionals [CHPs]). At the time of the survey, the AAFP membership database included 68,300 active members working in primary care. The ACHA membership database included 2931 health care professionals working at college health centers across the United States. The ACHA target group included all registered members from all regions of the United States, from the sections of Advanced Practice Clinicians, Clinical Medicine, Nurse-Directed Health Services, and Nursing. The makeup of the final ACHA sample included 91 physicians, 369 nursing professionals, 24 other specialists (clinical psychologists, social workers), and 12 physician assistants; 77 had no identified role or credentials. Only the health professionals from these 2 samples, and not their young-adult and student patients, were invited to participate in this survey.

\section{Survey Development}

The project team developed a survey in collaboration with 3 ADHD experts (a family physician, a pediatrician, and an ADHD research expert). We followed the best practices in survey development and reporting described by Kelley et al. ${ }^{12}$ The details of the survey development and administration methodology are described in Appendix 1. Briefly, the survey was developed based on key themes derived from the literature review. The survey included the following constructs: knowledge and belief; practice; risk management; strategies, and resources. Initially, 77 survey items were developed; these were further refined into a 43item questionnaire. We piloted the 43-item survey with 10 practicing physicians to evaluate their comprehension of the questions and answer choices. The final survey consisted of 42 items. We created 2 versions of the survey: article and online. The survey was administered between October 27, 2015, and January 31, 2016. 


\section{Statistical Analyses}

After the data were cleaned for duplicates and errors and scale items were recoded for consistency, descriptive statistics (overall, AAFP members, and ACHA members) for all questions were completed. For the binary and multiple-choice questions, the data are reported as counts and percentage. For the 5 -point Likert scale questions, the mean and SD was calculated for each group for each question. The lower the value of the mean, the more agreeable the statement is to the group's perceptions, feelings, or knowledge (for example, the scale $1=$ Describes me completely/Always/Very likely to $5=$ Does not describe me at all/Never/Very unlikely). For the analysis, 95\% CIs (not shown) and $t$-tests comparing AAFP members and ACHA members were completed for the Likert scale questions of interest. For the yes/no and multiple-select questions of interest, $\chi^{2}$ tests comparing AAFP members and ACHA members were completed. An $\alpha$ of 0.05 was used throughout the analysis. When a statistically significant difference existed between FPs and CHPs, it is specified in the results; if no difference was identified, the data are presented for all respondents combined. All analyses were conducted with SPSS (IBM SPSS Statistics for Windows, Version 22.0., Armonk, NY). Select questions are included in the results. All responses are included in Appendix 2.

\section{Results}

\section{Participant Characteristics}

Overall, 817 participants returned surveys, including 678 AAFP members and 139 ACHA members (response rates: $33.9 \%$ and $24.3 \%$, respectively). Several surveys were excluded from the analysis due to duplicate entries, incomplete surveys, or the respondent indicated she/he was retired, leaving the valid final sample of 794 respondents included in the analyses. Most of the surveys ( $\mathrm{n}=726 ; 91.4 \%$ ) were completed on article and the remainder $(\mathrm{n}=$ $68 ; 8.6 \%$ ) were completed online.

The average age of respondent was $51.6 \pm 10.3$ years, and the majority $(80.0 \%)$ of respondents indicated their race/ethnicity was white (FPs: 79.0\%; CHPs: $84.7 \%$ ) with no differences between the groups (Table 1). Overall, slightly over half $(50.6 \%)$ of the respondents were female with more female participants among CHPs (80.2\% vs $44.8 \%$ among FPs, $P<.01)$. More CHPs than FPs indi- cated that they are employed by a hospital, clinic, or university $(82.9 \%$ vs $45.5 \% ; P<.01)$. The majority of CHPs (80.6\%) reported they spend $75 \%$ to $100 \%$ of their time with patients 17 to 24 years of age; $74.0 \%$ of FPs reported they spend less than $25 \%$ of their time with the patient in this age group $(P<.01)$.

The sample of AAFP members in this study was largely representative of the overall AAFP membership based on gender, race, and years since residency, with the only exception of age distribution: the AAFP survey respondents were more evenly split between the 4 age categories than the overall AAFP member demographics $(<40$ years old: $15.9 \%$ vs $47.1 \%$; 40 to 49 years old: $24.3 \%$ vs $18.1 \%$; 50 to 59 years old: $33.6 \%$ vs $15.6 \% ; 60$ years and older: $26.1 \%$ vs $19.1 \%)$. The representativeness of the ACHA respondents could not be established due to limited available data.

\section{Knowledge and Belief}

The majority (80.6\%) of respondents estimated ADHD prevalence to be between $1 \%$ and $10 \%$ in adults, with more CHPs than FPs estimating a higher prevalence of ADHD in adults and college students $(P<.01)$. Although $54.4 \%$ of participants believed that ADHD is overdiagnosed in teens and young adults, $78.6 \%$ reported it is "likely or very likely" that they have adult patients with undiagnosed ADHD in their practice. The majority $(91.7 \%)$ of the respondents indicated that untreated ADHD affects quality of life, and 76.4\% indicated untreated ADHD is often associated with risky behaviors. More FPs than CHPs indicated ADHD is easy to "fake" for drug-seeking patients, and it is difficult to determine when a patient is "faking" the symptoms of ADHD (66.7\% vs $50.8 \%, P<.01$; and $64.5 \%$ vs $43.1 \%, P<.01$, respectively).

Overall, respondents agreed that stimulants have the potential for abuse $(98.7 \%)$ and that stimulants are addictive $(71.7 \%)$. The majority of respondents (81.2\%) were concerned with ADHD medication diversion, and $84.2 \%$ believed that diversion or abuse is a problem. Almost all know the correct definition of misuse, abuse, and diversion (97.9\%, $95.8 \%$, and $95.6 \%$, respectively). Over three fourths $(83.6 \%)$ agree that the legal consequences of diversion are serious, and $81.2 \%$ agree that it is important to educate about the legal ramifications of diversion. 
Clinician Age Group

$<40$ years old

40 to 49 years old

50 to 59 years old

60 years and older

Total

Gender

Male

Female

Total

Race/Ethnicity

American Indian or Alaskan Native

Asian

Black or African American

Spanish, Hispanic, or Latino

White

Native Hawaiian or Pacific Islander

Multiple races

Some other race or origin

Total

Practice Region (Census Region)

\section{Northeast}

Midwest

South

West

Total

Years since residency

0 to 10 years

11 to 20 years

21 to 30 years

31 years or more

Total

Which of the following duties account for most of your time in a typical week?

Outpatient primary care in office-based practice

Administration or managerial tasks not directly related to patient care

Research

Teaching

Urgent Care

Emergency Care

Other

Total
$75(11.5)$

$212(32.4)$

$219(33.5)$

148 (22.6)

654

$156(23.9)$

$192(29.4)$

$184(28.1)$

122 (18.7)

654

$12(9.4)$

35 (27.6)

$52(40.9)$

$28(22.0)$

127

$116(14.9)$

$194(24.8)$

$272(34.8)$

$199(25.5)$

781

$\mathrm{t}=-0.62$

390 (49.4)

$400(50.6)$

790

$\mathrm{X}^{2}=0.00$

$12(1.5)$

$56(7.1)$

32 (4.0)

18 (2.3)

$635(80.0)$

$6(0.8)$

$21(2.6)$

$14(1.8)$

794

$\mathrm{t}=-1.68$

$119(15.2)$

240 (30.7)

263 (33.6)

161 (20.6)

783

$\mathrm{t}=5.08^{*}$

$176(23.2)$

235 (31.0)

$320(27.7)$

138 (18.2)

759

$\mathrm{t}=0.53$

523 (79.6)

70 (55.6)

$593(75.7)$

16 (2.4)

16 (12.7)

$32(4.1)$

$1(0.2)$

$0(0.0)$

$1(0.1)$

0 (0.0)

$15(1.9)$

$26(4.0)$

$4(3.2)$

$30(3.8)$

$0(0.0)$

$21(2.7)$

36 (28.6)

91 (11.6)

783

$\mathrm{t}=-4.22^{*}$ 


\begin{tabular}{|c|c|c|c|}
\hline & AAFP, N (\%) & ACHA, N (\%) & Total, N (\%) \\
\hline \multicolumn{4}{|l|}{$\begin{array}{c}\text { Which of the following best describes your role in the } \\
\text { ownership of your primary clinical practice? }\end{array}$} \\
\hline A full or partial owner of your practice & $199(30.1)$ & $2(1.6)$ & $201(25.4)$ \\
\hline Employee of a physician-owned practice & $70(10.6)$ & $6(4.7)$ & $76(9.6)$ \\
\hline Employee of a hospital, clinic, or university & $301(45.5)$ & $107(82.9)$ & $408(51.6)$ \\
\hline $\begin{array}{l}\text { Employee of a managed care organization or insurance } \\
\text { company }\end{array}$ & $36(5.4)$ & $1(0.8)$ & $37(4.7)$ \\
\hline None of these & $55(8.3)$ & $13(10.1)$ & $68(8.6)$ \\
\hline Total & 661 & 129 & $\begin{array}{c}790 \\
\mathrm{t}=-7.90^{*}\end{array}$ \\
\hline \multicolumn{4}{|l|}{$\begin{array}{l}\text { About how much of your time in practice is spent working with } \\
\text { patients } 17 \text { to } 24 \text { years of age? }\end{array}$} \\
\hline None & $11(1.7)$ & $1(0.8)$ & $12(1.5)$ \\
\hline Less than $25 \%$ & $490(74.0)$ & $5(3.9)$ & $495(62.6)$ \\
\hline $25 \%$ to $49 \%$ & $127(19.2)$ & $7(5.4)$ & $134(16.9)$ \\
\hline $50 \%$ to $74 \%$ & $14(2.1)$ & $12(9.3)$ & $26(3.3)$ \\
\hline $75 \%$ to $100 \%$ & $17(2.6)$ & $104(80.6)$ & $121(15.3)$ \\
\hline Other & $3(0.5)$ & $0(0.0)$ & $3(0.4)$ \\
\hline Total & 662 & 129 & $\begin{aligned} & 791 \\
\mathrm{t}= & -33.48^{*}\end{aligned}$ \\
\hline
\end{tabular}

AAFP, American Academy of Family Physicians; ACHA, American College Health Association. ${ }^{*} P<.05$.

For FPs, the most frequent patient characteristics that are associated with abuse or diversions were history of drug use (80.8\%), history of mental illness $(61.1 \%)$, and male gender (49.3\%). For CHPs, most frequent patient characteristics that are associated with abuse or diversions were: history of drug use $(62.1 \%)$, competitive school or program $(61.3 \%)$, and male gender $(45.2 \%)$. The respondents believed that most patients only occasionally are engaged in nonmedical use or diversion of stimulants and much fewer patients engage very frequently. Fewer CHPs than FPs believed that their patients never or rarely engage in misuse, abuse, or diversion $(8.2 \%$ vs $17.0 \% ; 19.6 \%$ vs $25.7 \%$; and $17.5 \%$ vs $30.0 \%$, respectively).

\section{Practice}

In describing evaluation, diagnosis, and treatment for adult ADHD, more CHPs than FPs always refer out for diagnosis $(70.7 \%$ vs $52.1 \%, P<.05)$, seek expert consultation for diagnosis and treatment $(48.0 \%$ vs $19.1 \%, P<.05)$, never initiate drug therapy $(42.2 \%$ vs $15.1 \%, P<.05)$, and never use a stimulant as their first choice for ADHD treatment $(37.6 \%$ vs $13.1 \%, P<.05)$. More than one third of respondents reported that they never follow medication treatment recommendations $(38.6 \%)$, and more than half always discuss effects and side effects of stimulants with patients (54.0\%). See Table 2.

More FPs than CHPs reported they felt comfortable prescribing stimulants $(3.17 \pm 1.20$ vs $3.64 \pm 1.37, P<.05)$, tended to try medication even when uncertain $(4.51 \pm 0.77$ vs $4.79 \pm 0.50$, $P<.05)$, and believed treatment should be withdrawn if side effects emerge (2.72 \pm 1.12 vs $3.42 \pm$ $1.20, P=.05)$. More FPs than CHPs were not concerned with suicidal ideation or depression when prescribing stimulants $(4.5 \pm 0.9$ vs $4.77 \pm$ $0.7, P<.05)$. About a quarter of FPs $(23.0 \%$ vs $11.5 \%$ of CHPs) believed "medication holidays" were acceptable, with the differences in FPs' responses compared with CHPs' $(2.5 \pm 1.23$ vs $3.3 \pm$ 1.38, $P<.05$; see Table 2).

When asked about specific stimulant medications approved for treatment of ADHD in adults, for 9 medications (brand names) included in the survey, CHPs selected "not applicable" more frequently than FPs $(44.2 \%$ vs $14.1 \%, P<.05)$. Top 2 medications prescribed by most FPs (Figure 1) versus most CHPs (Figure 2) more than $50 \%$ of the time were Adderall XR and Adderall $(25 \%$ and 


\begin{tabular}{|c|c|c|c|c|c|c|}
\hline \multicolumn{2}{|c|}{ AAFP } & \multicolumn{2}{|c|}{ ACHA } & \multicolumn{3}{|c|}{ Differences } \\
\hline Mea & SD & Mean & SD & Mean & SD & $\mathrm{T}$ \\
\hline
\end{tabular}

Please select how often you offer or perform any of the following with the patients with ADHD in your practice:

Seek expert consultation in diagnosing and treating.

Follow a medication treatment algorithm such as the Texas algorithm or other recommendations.

Make a specific visit to evaluate for ADHD

Initiate any type of drug therapy for ADHD

Use a stimulant as your first choice for ADHD treatment.

Combine medication with other treatment recommendations such as organizational skills training, behavioral counseling.

Discuss side effects with patients.

Please select how well each of the following describes you:

I feel comfortable about prescribing stimulant medication.

I tend to try medication even when uncertain about the diagnosis.

I believe treatment should be withdrawn if side effects emerge.

The emergence of common side effects does not alter my treatment plan.

I am not prescribing stimulant medications because I have many concerns about side effects.

I always screen for depression before prescribing ADHD medication.

I always screen for suicidal ideation before prescribing ADHD medication.

I am not concerned with suicidal ideation or depression when prescribing ADHD medication.

I believe "medication holidays" are acceptable.

$\begin{array}{lllllll}2.52 & 1.09 & 1.91 & 1.04 & 0.61 & 0.11 & 5.77^{*} \\ 3.88 & 1.11 & 3.55 & 1.47 & 0.33 & 0.14 & 2.26^{*} \\ & & & & & & \\ 2.52 & 1.33 & 2.92 & 1.73 & -0.40 & 0.17 & -2.40^{*} \\ 3.04 & 1.10 & 3.78 & 1.33 & -0.75 & 0.13 & -5.79^{*} \\ 2.73 & 1.14 & 3.49 & 1.39 & -0.76 & 0.14 & -5.54^{*} \\ 2.65 & 1.15 & 2.83 & 1.44 & -0.19 & 0.14 & -1.34 \\ & & & & & & \\ 1.71 & 1.04 & 1.99 & 1.22 & -0.28 & 0.12 & -2.35^{*} \\ & & & & & & \\ 3.17 & 1.20 & 3.64 & 1.37 & -0.47 & 0.14 & -3.45^{*} \\ 4.51 & 0.77 & 4.79 & 0.50 & -0.28 & 0.06 & -5.03^{*} \\ 2.72 & 1.12 & 3.42 & 1.20 & -0.70 & 0.12 & -6.09^{*} \\ 3.95 & 1.02 & 3.94 & 1.08 & 0.02 & 0.11 & 0.14 \\ & & & & & & \\ 4.48 & 1.00 & 4.52 & 0.95 & -0.04 & 0.10 & -0.41 \\ & & & & & & \\ 2.62 & 1.25 & 2.77 & 1.61 & -0.15 & 0.16 & -0.91 \\ 2.64 & 1.30 & 2.76 & 1.63 & -0.12 & 0.16 & -0.76 \\ 4.50 & 0.91 & 4.77 & 0.66 & -0.27 & 0.07 & -3.70^{*} \\ 2.52 & 1.23 & 3.31 & 1.38 & -0.79 & 0.14 & -5.70^{*}\end{array}$

The following questions pertain to the college students 17 to 26 years of age. Please select how well each of the following statements describes you:

I always ask about patient's use of other substances.

I always discuss the stimulant diversion and misuse with my ADHD patients.

I always suggest available resources and support services (behavioral therapy, counseling) to my patients with ADHD.

How often do you feel education about ADHD or ADHD medication should occur?

How well do you feel you are equipped to provide patient education about each of the following:

Nature of ADHD

Effects and side-effects of stimulant medications.

Decisions about pharmacotherapy or behavioral therapy choices.

General expectations for college life such as stress, academic performance, conduct, life skills and preparation strategies.

Risky behaviors, drug abuse, medication misuse and prevention strategies.

$\begin{array}{rrrrrrr}2.56 & 0.88 & 2.58 & 0.95 & -0.03 & 0.09 & -0.28 \\ 2.35 & 0.84 & 2.38 & 0.94 & -0.04 & 0.09 & -0.39 \\ 2.61 & 0.88 & 2.69 & 1.09 & -0.08 & 0.11 & -0.78 \\ 2.44 & 0.87 & 1.90 & 0.82 & 0.54 & 0.08 & 6.41^{*} \\ 2.52 & 0.83 & 2.24 & 0.94 & 0.28 & 0.09 & 3.08^{*}\end{array}$

AAFP, American Academy of Family Physicians; ACHA, American College Health Association; ADHD, attention deficit hyperactivity disorder; SD, Standard deviation; T, T-value (t-statistic).

The mean was calculated for each group for each question. The lower the value of the mean, the more the agreeable the statement is to the group's perceptions, feelings, or knowledge. Scale is 1 to 5 with $1=$ Describes me completely/Always/Very likely to $5=$ Does not describe me at all/Never/Very unlikely. ${ }^{*} P<.05$.

$25 \%$ vs $25 \%$ and $16.9 \%$ respectively). Among FPs and CHPs, the most frequent factors associated with prescribing a certain medication were: previ- ous success with the same medicine $(75.2 \%$ vs $49.6 \%)$, comfort with medicine (74.4\% vs $43.0 \%$ ), insurance coverage or coverage restrictions $(72.8 \%$ 
Figure 1. FPs' frequency in prescribing ADHD medications. Abbreviations: FPs, family physicians; ADHD, attention deficit hyperactivity disorder.

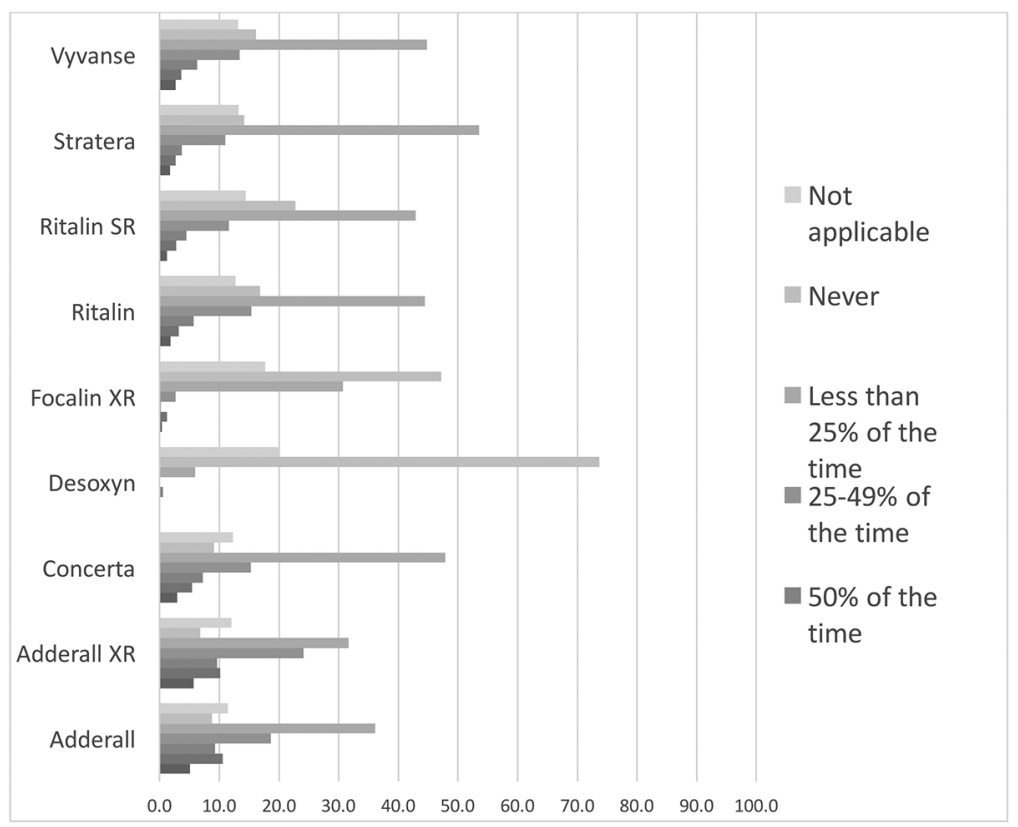

vs $42.1 \%)$, and cost of medication $(62.7 \%$ vs 39.7\%). More CHPs than FPs selected evidencebased guidelines (36.6\% vs $31.8 \%$ ) as 1 of the factors associated with prescribing a certain medication. More FPs than CHPs selected own experience $(40.4 \%$ vs $20.7 \%$ ) and patient preferences as important factors (36.8\% vs $19.8 \%$ ).

\section{Risk Management}

When asked specifically about misuse and diversion risk management in college students, CHPs more often than FPs would ask about a patient's other substance use $(1.86 \pm 1.1$ vs $2.16 \pm 1.1 ; P<.05)$ and suggest available resources to their ADHD patients $(2.04 \pm 1.2$ vs $2.55 \pm 1.2 ; P<.05)$. In monitoring

Figure 2. CHPs' frequency in prescribing ADHD medications. Abbreviations: CHPs, college health professionals; ADHD, attention deficit hyperactivity disorder.

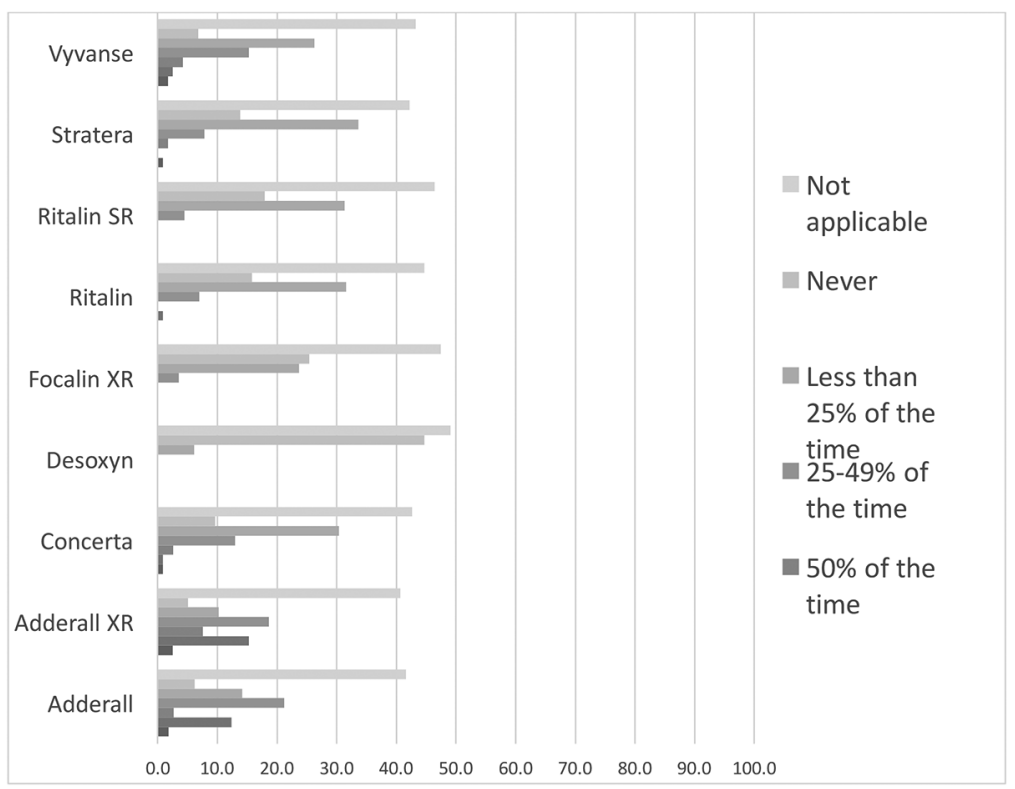


their patients' medication compliance, more FPs than CHPs indicated that they use a state medication registry $(62.1 \%$ vs $40.2 \%, P<.05)$, random drug testing $(42.3 \%$ vs $21.3 \% P<.05)$, and pill counts ( $18.6 \%$ vs $9.8 \%, P<.05$, see Table 3$)$.

Most participants indicated that they feel responsible for educating patients with $\mathrm{ADHD}$, with more FPs than CHPs agreeing with this responsibility $(95.1 \%$ vs $90.4 \% ; P=.04)$. The majority of participants agreed that they are responsible for educating about the legal, health, social, and physical risks of misuse and the mental effects of not using the medicine properly (see Table 3 ).

\section{Strategies and Resources}

Both FPs and CHPs indicated that the best way to educate patients was through education or counseling at the visits where the prescription was given (83.8\%). More CHPs than FPs $(16.1 \%$ vs $6.4 \%$;

Table 3. Analysis Results of Binary Scale Questions

\begin{tabular}{|c|c|c|c|c|}
\hline & \multirow[b]{2}{*}{ AAFP, \% } & \multirow[b]{2}{*}{ ACHA, \% } & \multicolumn{2}{|c|}{ Pearson $\chi^{2}$} \\
\hline & & & Value & Sig. \\
\hline \multicolumn{5}{|l|}{$\begin{array}{l}\text { How do you monitor your ADHD patient's medication compliance } \\
\text { (please select all that apply): }\end{array}$} \\
\hline I use a state medication registry to track patient prescription drug use. & 62.1 & 40.2 & 20.31 & $0.00^{*}$ \\
\hline I use random urine drug testing (UDT). & 42.3 & 21.3 & 18.96 & $0.00^{*}$ \\
\hline I use pill counts. & 18.6 & 9.8 & 5.48 & $0.02^{*}$ \\
\hline \multicolumn{5}{|l|}{$\begin{array}{l}\text { Which factors contribute to your decisions on which stimulant } \\
\text { medication to use (can choose more than one answer): }\end{array}$} \\
\hline Preference for fast acting over slow release stimulants. & 9.3 & 14.9 & 3.42 & 0.06 \\
\hline Preference for slow release over fast acting stimulants. & 40.1 & 35.5 & 0.9 & 0.34 \\
\hline Do you feel it is your responsibility to educate patients with ADHD? & 95.1 & 90.4 & 4.36 & $0.04^{*}$ \\
\hline \multicolumn{5}{|l|}{ If yes, what do you feel you are responsible for? } \\
\hline Educating about legal risks of misusing the medicine. & 67.2 & 74.3 & 2.23 & 0.14 \\
\hline Educating about the health and physical risks of misusing the medicine. & 92.2 & 88.5 & 1.72 & 0.19 \\
\hline Educating about the mental effects of not using the medicine properly. & 73.2 & 72.6 & 0.02 & 0.89 \\
\hline $\begin{array}{l}\text { Educating about how misusing medicine can affect social life and } \\
\text { relationships such as family, job, friends and significant others. }\end{array}$ & 63.6 & 66.4 & 0.32 & 0.57 \\
\hline \multicolumn{5}{|l|}{$\begin{array}{l}\text { What do you feel is the best way to educate patients about ADHD } \\
\text { (please select all that apply): }\end{array}$} \\
\hline Pamphlets and handouts. & 47.9 & 38.7 & 3.54 & 0.06 \\
\hline Education or counseling session at visits where prescription is written. & 83 & 87.9 & 1.86 & 0.17 \\
\hline Give the patient links to web resources. & 46.7 & 48.4 & 0.13 & 0.72 \\
\hline Mass media such as television and magazines. & 6.4 & 4 & 1.01 & 0.32 \\
\hline Social media such as Facebook and Twitter. & 6.4 & 16.1 & 13.43 & $0.00^{*}$ \\
\hline \multicolumn{5}{|l|}{$\begin{array}{l}\text { What do you feel you personally should be doing to reduce the misuse } \\
\text { of ADHD medications (please select all that apply): }\end{array}$} \\
\hline $\begin{array}{l}\text { Evaluate each patient with suspected ADHD to confirm diagnosis } \\
\text { before prescribing. }\end{array}$ & 83.5 & 67.2 & 17.42 & $0.00^{*}$ \\
\hline Refer all ADHD patients to mental health professionals for care. & 26.9 & 37.7 & 5.87 & $0.02 *$ \\
\hline $\begin{array}{l}\text { Educate patients with ADHD about how the stimulants should and } \\
\text { should not be used. }\end{array}$ & 76.9 & 79.5 & 0.38 & 0.54 \\
\hline $\begin{array}{l}\text { Provide clear instructions regarding sharing and selling medications to } \\
\text { patients with ADHD. }\end{array}$ & 67.4 & 59.8 & 2.62 & 0.11 \\
\hline $\begin{array}{l}\text { Provide specific instructions on how to dispose of any unneeded } \\
\text { medications. }\end{array}$ & 39.7 & 43.4 & 0.58 & 0.45 \\
\hline $\begin{array}{l}\text { Strictly monitor patient's prescription medication use with urine drug } \\
\text { tests and state registries. }\end{array}$ & 49 & 28.7 & 16.93 & $0.00^{*}$ \\
\hline $\begin{array}{l}\text { Educate all patients of college age about misuse and risk of misusing } \\
\text { stimulants. }\end{array}$ & 66.5 & 76.2 & 4.49 & $0.03^{*}$ \\
\hline Discourage "medication holidays." & 11.1 & 18 & 4.53 & $0.03^{*}$ \\
\hline
\end{tabular}

AAFP, American Academy of Family Physicians; ACHA, American College Health Association; ADHD, attention deficit hyperactivity disorder. ${ }^{*} P<.05$. 
$P<.01)$ indicated social media was a way to educate patients about ADHD (see Table 3).

When asked about which aspects of patient education the respondents are more or less comfortable in providing, some FPs and CHPs reported they were well equipped to handle patient education on the nature of ADHD, effects and side effects of stimulants, and decisions about therapy choices. Compared with FPs, more CHPs indicated they are equipped to provide patient education on general expectations for college life and on risky behaviors, drug abuse, medication misuse, and prevention strategies (see Table 2). However, there were areas where the majority of FPs and CHPs feel they are somewhat unprepared to not prepared at all. For FPs, the majority indicated they are unprepared in the areas of:

- Decisions about pharmacotherapy or behavioral therapy choices $(52.9 \%)$

- Risky behaviors, drug abuse, medication misuse, and prevention strategies (52.4\%)

- Nature of ADHD (50.7\%).

For CHPs, the majority indicated they are unprepared in the areas of:

- Decisions about pharmacotherapy or behavioral therapy choices $(59.5 \%)$

- Nature of ADHD (58.9\%)

- Effects and side effects of stimulant medications (50.4\%).

When asked about provider education strategies, FPs and CHPs indicated that Continuing Medical Education (CME)/conferences (93.2\%), journal articles (73.7\%), other physicians/peer groups (58.7\%), and professional associations $(56.3 \%)$ would all have the potential to impact physicians' views on misuse prevention. Over one quarter of all respondents $(27.0 \%)$ indicated that media (TV, Internet) may also influence physicians' views on abuse, misuse, and diversions issues.

\section{Discussion}

FPs and CHPs play an important role in the management of teens and young adults with ADHD and stimulant prescribing. ${ }^{13,14}$ Several qualitative studies reported on physicians' challenges related to adult ADHD diagnosis, management, and treatment, and some explored issues related to misuse, abuse, and diversion. ${ }^{15-17}$ To our knowledge, this is the first US national and systematic description of FPs' and CHPs' self-reported perceptions and practice patterns focusing on pharmacological treatment and prevention of nonmedical use and diversion of stimulants among teens and young adults. This article presents and discusses the survey results and highlights selected findings and their implications while also presenting the detailed report of all collected data for further interpretations. The most significant key findings are highlighted below.

Similar to previous studies, we found that an overwhelming majority of surveyed FPs and CHPs whose patient populations include teens, young adults, and college students agree that untreated ADHD negatively affects quality of life., 38,19 However, many FPs and CHPs in our study believe that some of their patients may have undiagnosed and untreated ADHD. These results suggest a continued need to support appropriate identification of untreated ADHD among adults and young adults. Effective detection of ADHD in adults needs to consider reported difficulties among many providers with identifying patients with ADHD who actually have symptoms and would benefit from treatment from those who may "fake" the symptoms to gain access to stimulants for nonmedical use. ${ }^{20,21}$ This difficulty expressed by the clinicians may be due to generally low to moderate levels of competence and comfort of primary care practitioners with assessment and diagnosis of ADHD in teens and adults. ${ }^{22-24}$ Many participants reported they always refer out for diagnosis and seek expert consultation for treatment.

Most participants agree that diversion or abuse of stimulant medications is a problem and feel responsible for educating patients about legal, health, and physical risks of stimulant use and misuse. While half of participants believed that patients occasionally engaged in abuse, diversion and misuse of stimulants, FPs reported believing their patients engaged less frequently in nonmedical use 
than what CHPs believed. Unlike FPs, significantly more CHPs believe that patients with ADHD frequently or very frequently divert their medications by giving them to friends or selling them. Recent studies show that around $70 \%$ of college students who have a prescription for stimulants diverted medication at least once in their lifetime, mostly via sharing. ${ }^{25,26}$ Similar patterns have been reported for misuse; while most students do use their ADHD medication as prescribed, misuse and diversion is not uncommon. ${ }^{27}$ Even though only a very small percentage of prescription holders engages in frequent diversion, abuse, or misuse of their medications, nonmedical use-related behaviors should be identified, and prevention efforts aimed at reducing these behaviors should be considered.

The results of our study point to some potential areas where future initiatives for quality improvement, research, and education can be considered. For example, in describing their practices, only half of participants reported always discussing medication effects and side effects with their patients, and many do not feel well prepared in discussing all treatment options with the patients. Not many prescribers use drug compliance monitoring strategies such as state medical registries, urine drug tests, and pill counts. These observations provide an opportunity to support providers with tools and resources on responsible patient education, shared decision making, and risk reduction.

Overall, FPs and CHPs were similar in many aspects related to evaluation and management of ADHD. Noticeable differences were identified, however, with the FPs reporting using stimulants as first choice and feeling confident with stimulant prescribing more often than CHPs. It is important to note that while many CHPs see patients with $\mathrm{ADHD}$, the majority reported that they do not prescribe stimulants or initiate any drug therapy for ADHD. Even though we have not explored the actual reasons in the survey, this may be due to limited prescription privileges to psychologists and other health professionals on campus. This finding highlights the need for further explorations and programs to support transition of care across services for young adults with $\mathrm{ADHD}$ via either accessible referral resources or alternative care transition models to address potential discontinuity of mental health care and gaps in treatment. ${ }^{28}$
Our results are consistent with other studies that identified physicians' low level of confidence in medication management of ADHD with high level of concerns about stimulant medications. ${ }^{29} \mathrm{Al}-$ though more FPs than CHPs felt comfortable with prescribing stimulants, many FPs reported they prescribe based on their own success and comfort with medications and their own clinical judgment rather than evidence-based guidelines. These findings are not surprising, as there are no evidencebased primary care-focused US-specific treatment algorithms and practice guidelines for adult ADHD in the US. Moreover, only one third of prescribers reported they consider patient preferences when deciding on which medication to use. This points to the need to establish evidence-based practice guidelines and shared decision making guides that account for the balance of harms and benefits of all available treatment options.

In addition, due to the lack of treatment standards and adult ADHD quality metrics, the reported practices and resulting quality of care are difficult to assess. ${ }^{30}$ For instance, some of the reported practices are not supported by sufficient level of evidence. For example, "medication holidays" were approved/encouraged by the substantial number of the providers in our study, though there is a paucity of research on the benefits and potentials risks of "medication holidays" among adults. ${ }^{31}$

Overall, FPs and CHPs are concerned with stimulant abuse, misuse, and diversion, and would benefit from additional information, education, and practice support through Continuing Medical Education (CME) opportunities, journal publications, conferences, and professional associations. The results of this study suggest that education, research, quality improvement, and prevention initiatives need to continue to focus on nonmedical use reduction to ensure safe and appropriate use of stimulants among young adults.

This study has some limitations that may affect the generalizability of results. The sociodemographic and practice characteristics of the FPs sample are comparable to the AAFP membership. However, it is not possible to generalize these results to FPs who are not AAFP members or the CHPs who did not participate in the survey. Furthermore, our study only involved family practice physicians and college health professionals. Pediatricians and other physician specialties involved in treating teenagers and young adults of college age 
with ADHD were not included. Despite the relatively high response rate for physicians, there might still be a response bias; the physicians with higher interest in mental health might have chosen to participate, hence their statements possibly may not be reflective of those who have low interest in mental health and ADHD, in particular.

This study was based on clinicians' self reports and did not evaluate knowledge and clinical behavior by objective measures. The relationship between opinions/attitudes and clinical behavior is controversial. $^{32,33}$ To that end, we do not know to what extent the self-reported practices correlate with the objective measures of clinicians' performance or quality of care, whether the occasional diversion or misuse of stimulant medications among young adults are viewed by physicians as benign, and what actions, if any, the clinicians actually choose when providing care to their actual patients. In addition, we did not guide our participants to think of specific patients or situations when answering questions and were limited in our ability to explore in depth factors that may have influenced the responses, including those related to the local ecosystems and infrastructure, the prescribing privileges, prioritizing treatment selection for specific subgroups of patients, local policies and mandates, and other factors related to participant's specific settings.

Finally, there are very few published reliable instruments assessing FPs' and CHPs' opinions, knowledge, and attitudes about ADHD and nonmedical use of stimulants. The survey instrument was developed and subsequently tested by the project team to include a limited number of questions related to only 4 constructs and to assure item relevance and comprehension. We did not evaluate the reliability and the validity of the survey instrument.

\section{Conclusion}

The results of this survey are an important step toward documenting knowledge on topics related to ADHD pharmacotherapy and nonmedical use of stimulants in young adults in family medicine and college health clinics. Additional resources and interventions are needed to address identified gaps for quality improvement related to medication management, misuse reduction, and interprofessional collaborations and continuation of care to ensure safe and appropriate use of stimulants. The result of this project will lead to better understanding of what strategies need to be implemented to improve ADHD care and to prevent and reduce issues related to inappropriate use of stimulants.

The authors thank all participants of this project. We would like to acknowledge the AAFP National Research Network for providing essential expertise, staff, and support.

To see this article online, please go to: http://jabfm.org/content/ 33/1/59. full.

\section{References}

1. Kessler RC, Adler L, Barkley R, et al. The prevalence and correlates of adult ADHD in the United States: results from the National Comorbidity Survey Replication. Am J Psychiatry 2006; 163:716-23.

2. Simon V, Czobor P, Bálint S, Mészáros A, Bitter I. Prevalence and correlates of adult attention-deficit hyperactivity disorder: meta-analysis. Br J Psychiatry 2009;194:204-11.

3. Weyandt LL, DuPaul G. ADHD in college students. J Atten Disord 2006;10:9-19.

4. Biederman J, Petty CR, Evans M, Small J, Faraone SV. How persistent is ADHD? A controlled 10-year follow-up study of boys with ADHD. Psychiatry Res 2010;177:299-304.

5. Faraone SV, Biederman J, Mick E. The age-dependent decline of attention deficit hyperactivity disorder: a meta-analysis of follow-up studies. Psychol Med 2006;36:159-65.

6. McCabe SE, West BT, Teter CJ, Boyd CJ. Trends in medical use, diversion, and nonmedical use of prescription medications among college students from 2003 to 2013: connecting the dots. Addict Behav 2014;39:1176-82.

7. Verdi G, Weyandt LL, Zavras BM. Non-medical prescription stimulant use in graduate students: relationship with academic self-efficacy and psychological variables. J Atten Disord 2016;20:741-53.

8. Wilens TE, Adler LA, Adams J, et al. Misuse and diversion of stimulants prescribed for ADHD: a systematic review of the literature. J Am Acad Child Adolesc Psychiatry 2008;47:21-31.

9. Arria AM, Caldeira KM, O'Grady KE, Vincent KB, Johnson EP, Wish ED. Nonmedical use of prescription stimulants among college students: associations with attention-deficit-hyperactivity disorder and polydrug use. Pharmacotherapy 2008;28:156-69.

10. Arria AM, DuPont RL. Nonmedical prescription stimulant use among college students: why we need to do something and what we need to do. J Addict Dis 2010;29:417-26. 
11. Chen LY, Strain EC, Crum RM, Storr CL, Mojtabai R. Sources of nonmedically used prescription stimulants: differences in onset, recency and severity of misuse in a population-based study. Drug Alcohol Depend 2014;145:106-12.

12. Kelley K, Clark B, Brown V, Sitzia J. Good practice in the conduct and reporting of survey research. Int J Qual Health Care 2003;15:261-6.

13. Post RE, Kurlansik SL. Diagnosis and management of adult attention-deficit/hyperactivity disorder. Am Fam Physician 2012;85:890-6.

14. Meaux JB, Green A, Broussard L. ADHD in the college student: a block in the road. J Psychiatr Ment Health Nurs 2009;16:248-56.

15. Knutson KC, O'Malley M. Adult attention-deficit/ hyperactivity disorder: A survey of diagnosis and treatment practices. J Am Acad Nurse Pract 2010; 22:593-601.

16. Weisler RH, Goodman DW. Assessment and diagnosis of adult ADHD: clinical challenges and opportunities for improving patient care. Primary Psychiatry 2008;15(11), 53-64.

17. Colaneri N, Keim S, Adesman A. Physician practices to prevent ADHD stimulant diversion and misuse. J Subst Abuse Treat 2017;74:26-34.

18. Agarwal R, Goldenberg M, Perry R, IsHak WW. The quality of life of adults with attention deficit hyperactivity disorder: a systematic review. Innov Clin Neurosci 2012;9:10-21.

19. Coghill, D. The impact of medications on quality of life in attention-deficit hyperactivity disorder: a systematic review. CNS Drugs 2010;24:843-66.

20. Sullivan BK, May K, Galbally L. Symptom exaggeration by college adults in attention-deficit hyperactivity disorder and learning disorder assessments. Appl Neuropsychol 2007;14:189-207.

21. Sansone RA, Sansone LA. Faking attention deficit hyperactivity disorder. Innov Clin Neurosci 2011;8: 10-3.

22. Faraone SV, Spencer TJ, Montano CB, Biederman J. Attention-deficit/hyperactivity disorder in adults: a survey of current practice in psychiatry and primary care. Arch Intern Med 2004;164:1221-6.

23. Lamberg, L. ADHD often undiagnosed in adults: appropriate treatment may benefit work, family, social life. JAMA 2003;290:1565-7.

24. Tatlow-Golden M, Prihodova L, Gavin B, Cullen W, McNicholas F. What do general practitioners know about ADHD? Attitudes and knowledge among first-contact gatekeepers: systematic narrative review. BMC Fam Pract 2016;17:129.

25. Garnier LM, et al. Sharing and selling of prescription medications in a college student sample. J Clin Psychiatry 2010;71:262-9.

26. Gallucci AR, Martin RJ, Usdan SL. The diversion of stimulant medications among a convenience sample of college students with current prescriptions. Psychol Addict Behav 2015;29:154-61.

27. Rabiner DL, Anastopoulos AD, Costello EJ, Hoyle $\mathrm{RH}, \mathrm{McCabe}$ SE, Swartzwelder HS. The misuse and diversion of prescribed ADHD medications by college students. J Atten Disord 2009;13:144-53.

28. Young S, Murphy CM, Coghill D. Avoiding the 'Twilight Zone': recommendations for the transition of services from adolescence to adulthood for young people with ADHD. BMC Psychiatry 2011;11:174.

29. Stockl KM, Hughes TE, Jarrar MA, Secnik K, Perwien AR. Physician perceptions of the use of medications for attention deficit hyperactivity disorder. J Manag Care Pharm 2003;9:416-23.

30. Faraone SV, Silverstein MJ, Antshel K, et al. The Adult ADHD Quality Measures Initiative. J Atten Disord. 2019;23:1063-78.

31. Ibrahim K, Donyai P. Drug holidays from ADHD medication: international experience over the past four decades. J Atten Disord 2015;19:551-68.

32. Montaño DE, Phillips WR. Cancer screening by primary care physicians: a comparison of rates obtained from physician self-report, patient survey, and chart audit. Am J Public Health 1995;85:795-800.

33. Cabana MD, et al. Why don't physicians follow clinical practice guidelines? A framework for improvement. JAMA 1999;282:1458-65. 


\section{Appendix}

\section{Detailed Survey Development and Administration Methodology Construct Development (Key Issues)}

The project team developed a survey with collaboration with 3 experts in treating ADHD (a family physician, a pediatrician, and an ADHD research expert). The survey was developed based on key themes derived from the literature review data (See below for search criteria). The literature review was conducted in March-June, 2015, and resulted in 668 initial articles. The research team assessed the article titles and abstracts for eligibility, and reviewed full texts of 36 to inform the contents of the survey. The articles were eligible if they included survey methodology and survey results on a topic of ADHD and medical and nonmedical use of stimulants. The reporting of results of the literature review is beyond the scope of this work. The survey included the following constructs: knowledge and belief; practice; risk management; strategies and resources.

\section{Search Terms}

("attention deficit disorder with hyperactivity" $[\mathrm{MeSH}$ Terms] OR "attention deficit disorder with hyperactivity"[All Fields] OR "adhd"[All Fields] OR "Attention Deficit and Disruptive Behavior Disorders" [MeSH Terms] OR "Attention Deficit and Disruptive Behavior Disorders"[All Fields]) AND ("treatment"[All Fields] OR "guidelines"[All Fields] OR "treatment guidelines"[All Fields] OR “recommendation"[All Fields] OR "best practice"[All Fields] OR "current practice"[All Fields] OR "clinical decision algorithm"[All Fields]) AND “adult"[MeSH Terms] AND “2009/10/09”[PDAT] : “2014/10/07”[PDAT] AND English[lang].

\section{Draft Survey Questions}

Survey items under each construct were developed based on existing items extracted from the literature review and from information derived from an expert panel. The process resulted in 77 survey items plus a demographics section; these were further refined into a 43-item questionnaire.

\section{Pilot and Refine the Questionnaire}

We piloted the 43 -item survey with 10 practicing physicians to evaluate their comprehension of the questions and answer choices. The pilot group also rated the quality of each question on a 5-point scale (excellent, very good, good, fair and poor) and provided suggestions for improvement. After revisions, the final survey consisted of 42 items including 9 items collecting respondents' demographic information and 1 open-ended question that asks respondents to share any thoughts about the topic of ADHD or stimulant misuse, abuse, or diversion among young adults.

We created 2 versions of the survey: article and on-line. The survey included a header with the AAFP brand, and was formatted to be compatible with the AAFP's optical scanner (Fujitsu fi-6670), the scanning software (ScandAll Pro, Fujitsu Computer Products of America, Inc., Sunnyvale, CA), and the data entry/reading software (ReMark, Remark, Malvern, PA). We also created an on-line version of the survey using Novi Survey. The online survey used the same question order, though formatting varied slightly to account for userfriendly experience on-line.

\section{Survey Administration}

Each survey was coded with the study identification number. The surveys were mailed with a formal AAFP cover letter and a prepaid return envelope. A 2-dollar bill was included with each survey.

An email, with a link to the survey, was sent just before the initial mailing on October 27, 2015, to those members with email addresses. The web link was offered as an alternative to completing the article form. An email reminder was sent to nonresponders 2 weeks following the initial mailing. A second article survey was mailed to nonresponders 5 weeks from the first mailing. The survey was closed on January 31, 2016. Completed surveys were sorted and scanned and manually corrected for mis-scanned responses and hand keyed for open ended answers. 
Appendix Table 1. Based on Your Understanding, How Prevalent is ADHD in Adults?

\begin{tabular}{lccc}
\hline & AAFP, $\mathrm{N}(\%)$ & ACHA, N (\%) & Total, N (\%) \\
\hline Less than $1 \%$ & $51(7.7)$ & $2(1.6)$ & $53(6.7)$ \\
$1 \%$ to $5 \%$ & $330(50.1)$ & $41(32.0)$ & $371(47.1)$ \\
$6 \%$ to $10 \%$ & $215(27.3)$ & $49(38.3)$ & $264(33.5)$ \\
$11 \%$ to $20 \%$ & $50(6.4)$ & $22(17.2)$ & $72(9.1)$ \\
Greater than $20 \%$ & $11(1.4)$ & $12(9.4)$ & $23(2.9)$ \\
Other & $2(0.3)$ & $2(1.6)$ & $4(0.5)$ \\
Total & 659 & 128 & 787 \\
\hline
\end{tabular}

AAFP, American Academy of Family Physicians; ACHA, American College Health Association; ADHD, attention deficit hyperactivity disorder.

Appendix Table 2. Based on Your Best Understanding, How Prevalent is ADHD Among College Students?

\begin{tabular}{lccc}
\hline & AAFP, $\mathrm{N}(\%)$ & ACHA, N (\%) & Total, N (\%) \\
\hline Less than $1 \%$ & $39(5.9)$ & $2(1.6)$ & $41(5.2)$ \\
$1 \%$ to $5 \%$ & $281(42.7)$ & $28(22.4)$ & $309(39.5)$ \\
$6 \%$ to $10 \%$ & $250(38.0)$ & $53(42.4)$ & $303(38.7)$ \\
$11 \%$ to $20 \%$ & $72(10.9)$ & $27(21.6)$ & $99(12.6)$ \\
Greater than $20 \%$ & $16(2.4)$ & $15(12.0)$ & $31(4.0)$ \\
Total & 658 & 125 & 783 \\
\hline
\end{tabular}

AAFP, American Academy of Family Physicians; ACHA, American College Health Association; ADHD, attention deficit hyperactivity disorder.

Appendix 3. How Likely Is it That You Have Adult Patients with Undiagnosed ADHD in Your General Practice?

\begin{tabular}{lccc}
\hline & AAFP, N (\%) & ACHA, N (\%) & Total, N (\%) \\
\hline Very likely & $197(30.1)$ & $41(32.3)$ & $238(30.4)$ \\
Likely & $316(48.2)$ & $61(48.0)$ & $377(48.2)$ \\
Neither likely nor unlikely & $67(10.2)$ & $10(7.9)$ & $77(9.8)$ \\
Unlikely & $63(9.6)$ & $11(8.7)$ & $74(9.5)$ \\
Very unlikely & $12(1.8)$ & $4(3.1)$ & $16(2.0)$ \\
Total & 655 & 127 & 782 \\
\hline
\end{tabular}

AAFP, American Academy of Family Physicians; ACHA, American College Health Association; ADHD, attention deficit hyperactivity disorder. 


\begin{tabular}{|c|c|c|c|}
\hline & AAFP, N (\%) & ACHA, N (\%) & Total, N (\%) \\
\hline \multicolumn{4}{|c|}{ ADHD is overdiagnosed in teens and young adults. } \\
\hline Strongly agree & $99(15.1)$ & $15(12.1)$ & $114(14.7)$ \\
\hline Agree & $264(40.4)$ & $45(36.3)$ & $309(39.7)$ \\
\hline Neither agree nor disagree & $172(26.3)$ & $35(28.2)$ & $207(26.6)$ \\
\hline Disagree & $114(17.4)$ & $29(23.4)$ & $143(18.4)$ \\
\hline Strongly disagree & $5(0.8)$ & $0(0.0)$ & $5(0.6)$ \\
\hline Total & 654 & 124 & 778 \\
\hline \multicolumn{4}{|c|}{ Untreated ADHD affects quality of life. } \\
\hline Strongly agree & $171(26.4)$ & $39(31.5)$ & $210(27.2)$ \\
\hline Agree & $419(64.8)$ & $78(62.9)$ & $497(64.5)$ \\
\hline Neither agree nor disagree & $47(7.3)$ & $7(5.6)$ & $54(7.0)$ \\
\hline Disagree & $4(0.6)$ & $0(0.0)$ & $4(0.5)$ \\
\hline Strongly disagree & $6(0.9)$ & $0(0.0)$ & $6(0.8)$ \\
\hline Total & 647 & 124 & 771 \\
\hline \multicolumn{4}{|c|}{$\begin{array}{l}\text { Untreated ADHD is often associated with risky } \\
\text { behaviors. }\end{array}$} \\
\hline Strongly agree & $131(20.3)$ & $34(27.9)$ & $165(21.5)$ \\
\hline Agree & $361(56.0)$ & $60(49.2)$ & $421(54.9)$ \\
\hline Neither agree nor disagree & $124(19.2)$ & $24(19.7)$ & $148(19.3)$ \\
\hline Disagree & $24(3.7)$ & $4(3.3)$ & $28(3.7)$ \\
\hline Strongly disagree & $5(0.8)$ & $0(0.0)$ & $5(0.7)$ \\
\hline Total & 645 & 122 & 767 \\
\hline \multicolumn{4}{|c|}{ ADHD is easy to "fake" for drug-seeking patients. } \\
\hline Strongly agree & $106(16.4)$ & $13(10.5)$ & $119(15.5)$ \\
\hline Agree & $325(50.3)$ & $50(40.3)$ & $375(48.7)$ \\
\hline Neither agree nor disagree & $146(22.6)$ & $40(32.3)$ & $186(24.2)$ \\
\hline Disagree & $67(10.4)$ & $21(16.9)$ & $88(11.4)$ \\
\hline Strongly disagree & $2(0.3)$ & $0(0.0)$ & $7(0.3)$ \\
\hline Total & 646 & 124 & 770 \\
\hline \multicolumn{4}{|c|}{$\begin{array}{l}\text { It is difficult to determine when a patient is } \\
\text { "faking" the symptoms of ADHD. }\end{array}$} \\
\hline Strongly agree & $69(10.7)$ & $6(4.9)$ & $75(9.8)$ \\
\hline Agree & $347(53.8)$ & $47(38.2)$ & $394(51.3)$ \\
\hline Neither agree nor disagree & $156(24.2)$ & $42(34.1)$ & $198(25.8)$ \\
\hline Disagree & $71(11.0)$ & $28(22.8)$ & $99(12.9)$ \\
\hline Strongly disagree & $2(0.3)$ & $0(0.0)$ & $2(0.3)$ \\
\hline Total & 645 & 123 & 768 \\
\hline
\end{tabular}

AAFP, American Academy of Family Physicians; ACHA, American College Health Association; ADHD, attention deficit hyperactivity disorder. 


AAFP, N (\%) $\quad$ ACHA, N (\%) $\quad$ Total, N (\%)

Seek expert consultation in diagnosing and treating.

Always
Very often
Sometimes
Rarely
Never
Total

$\begin{array}{ccc}123(19.1) & 59(48.0) & 182(23.7) \\ 210(32.6) & 26(21.1) & 236(30.7) \\ 192(29.8) & 31(25.2) & 223(29.0) \\ 91(14.1) & 4(3.3) & 95(12.4) \\ 29(4.5) & 3(2.4) & 32(4.2) \\ 645 & 123 & 768\end{array}$

Follow a medication treatment algorithm such as the Texas algorithm or other recommendations.

Always
Very often
Sometimes
Rarely
Never
Total

$14(2.2)$

$74(11.6)$

$129(20.2)$

$180(28.2)$

$242(37.9)$

639

Make a specific visit to evaluate for ADHD.

Always

Very often

Sometimes

Rarely

Never

Total

Initiate any type of drug therapy for ADHD.

Always

Very often

Sometimes

Rarely

Never

Total

Use a stimulant as your first choice for ADHD treatment.

Always

Very often

Sometimes

Rarely

Never

Total

Combine medication with other treatment recommendations such as organizational skills training, behavioral counseling.

Always

Very often

Sometimes

Rarely

Never

Total

Discuss effects and side effects of stimulants with patients.

Always

Very often

Sometimes

Rarely

Never

Total
$166(25.9)$

$211(33.0)$

109 (17.0)

$70(10.9)$

84 (13.1)

640

$28(4.4)$

$192(30.0)$

246 (38.4)

72 (12.2)

97 (15.1)

641

44 (6.9)

$304(47.9)$

$149(23.5)$

55 (8.7)

83 (13.1)

635

$$
\begin{gathered}
92(14.4) \\
238(37.2) \\
176(27.5) \\
70(11.0) \\
63(9.9) \\
639
\end{gathered}
$$
$353(55.2)$
$196(30.6)$
$42(6.6)$
$19(3.0)$
$30(4.7)$

640
27 (3.6)

94 (12.5)

$150(19.9)$

$191(25.4)$

291 (38.6)

753

$$
\begin{gathered}
205(27.0) \\
233(30.7) \\
118(15.5) \\
77(10.1) \\
126(16.6) \\
759
\end{gathered}
$$

$$
35(4.6)
$$

213 (28.0)

262 (34.4)

$101(13.3)$

$150(19.7)$

761

$53(7.0)$

331 (44.0)

172 (22.9)

$69(9.2)$

127 (16.9)

752

$\begin{array}{lr}44(37.6) & 752\end{array}$

115 (15.2)

$275(36.2)$

202 (26.6)

75 (9.9)

92 (12.1)

759

$414(54.3)$

$220(28.9)$

$63(8.3)$

$28(3.7)$

$37(4.9)$

762

AAFP, American Academy of Family Physicians; ACHA, American College Health Association; ADHD, attention deficit hyperactivity disorder. 


AAFP, N (\%) ACHA, N (\%) Total, N (\%)

ADHD often occurs with another mental health problem.

Strongly agree

Agree

Neither agree nor disagree

Disagree

Strongly disagree

Total

Stimulants have the potential for abuse.

Strongly agree

Agree

Neither agree nor disagree

Disagree

Strongly disagree

Total

Stimulants are additive.

Strongly agree

Agree

Neither agree nor disagree

Disagree

Strongly disagree

Total

There is a clear difference between diversion, misuse and abuse.

Strongly agree

Agree

Neither agree nor disagree

Disagree

Strongly disagree

Total

Diversion or abuse is a problem overall.

Strongly agree

Agree

Neither agree nor disagree

Disagree

Strongly disagree

Total

Diversion is a more serious issue than misuse or abuse.

Strongly agree

Agree

Neither agree nor disagree

Disagree

Strongly disagree

Total

The legal consequences of diversion for both yourself and patient are serious.

Strongly agree

Agree

Neither agree nor disagree

Disagree

Strongly disagree

Total

$\begin{array}{cc}102(15.8) & 20(16.1) \\ 378(58.6) & 62(50.0) \\ 122(18.9) & 31(25.0) \\ 40(6.2) & 10(8.1) \\ 3(0.5) & 1(0.8) \\ 645 & 124\end{array}$

$353(54.5)$

$289(44.6)$

$4(0.6)$

$2(0.3)$

$0(0.0)$

648

161 (24.9)

302 (46.7)

133 (20.6)

49 (7.6)

$1(0.2)$

646

$$
\begin{gathered}
71(57.3) \\
49(39.5) \\
3(2.4) \\
1(0.8) \\
0(0.0) \\
124
\end{gathered}
$$

$122(15.9)$

440 (57.2)

$153(19.9)$

$50(6.5)$

$4(0.5)$

769

$$
\begin{gathered}
424(54.9) \\
338(43.8) \\
7(0.9) \\
3(0.4) \\
0(0.0) \\
772
\end{gathered}
$$

$\begin{array}{cc}36(29.0) & 197(25.6) \\ 53(42.7) & 355(46.1) \\ 25(20.2) & 158(20.5) \\ 10(8.1) & 59(7.7) \\ 0(0.0) & 1(0.1) \\ 124 & 770\end{array}$

122 (18.9)

28 (22.6)

$150(19.5)$

295 (45.6)

$59(47.6)$

$121(18.7)$

23 (18.5)

98 (15.1)

$13(10.5)$

11 (1.7)

$1(0.8)$

354 (45.9)

144 (18.7)

111 (14.4)

12 (1.6)

647

124

771

190 (29.4)

21 (16.9)

211 (27.4)

357 (55.3)

$80(64.5)$

437 (56.8)

$82(12.7)$

$18(14.5)$

$100(13.0)$

$16(2.5)$

$5(4.0)$

$21(2.7)$

$1(0.2)$

$0(0.0)$

$1(0.1)$

124

770

$\begin{array}{ccc}61(9.5) & 16(12.9) & 77(10.0) \\ 168(26.1) & 37(29.8) & 205(26.7) \\ 304(47.3) & 52(41.9) & 356(46.4) \\ 103(16.0) & 17(13.7) & 120(15.6) \\ 7(1.1) & 2(1.6) & 9(1.2) \\ 643 & 124 & 767\end{array}$

\begin{tabular}{ccc}
$173(26.7)$ & $43(35.5)$ & $216(28.1)$ \\
$366(56.6)$ & $60(49.6)$ & $426(55.5)$ \\
$90(13.9)$ & $15(12.4)$ & $105(13.7)$ \\
$16(2.5)$ & $3(2.5)$ & $19(2.5)$ \\
$2(0.3)$ & $0(0.0)$ & $2(0.3)$ \\
647 & 121 & 768 \\
\hline
\end{tabular}

Continued 


AAFP, $\mathrm{N}(\%) \quad$ ACHA, $\mathrm{N}(\%) \quad$ Total, $\mathrm{N}(\%)$

You have concerns about diversion with ADHD medications.

$\begin{array}{lccc}\text { Strongly agree } & 164(25.4) & 37(30.3) & 201(26.2) \\ \text { Agree } & 360(55.8) & 62(50.8) & 422(55.0) \\ \text { Neither agree nor disagree } & 92(14.3) & 20(16.4) & 112(14.6) \\ \text { Disagree } & 29(4.5) & 2(1.6) & 31(4.0) \\ \text { Strongly disagree } & 0(0.0) & 1(0.8) & 1(0.1) \\ \text { Total } & 645 & 122 & 767\end{array}$

AAFP, American Academy of Family Physicians; ACHA, American College Health Association; ADHD, attention deficit hyperactivity disorder.

Appendix 7. Based on Your Best Understanding, for Each Statement Below Please Select Whether the Definition is True or False

AAFP, N (\%) $\quad$ ACHA, N (\%) $\quad$ Total, N (\%)

Misuse is intentional or unintentional use of stimulants in a way other than prescribed.

\begin{tabular}{|c|c|c|c|}
\hline TRUE & $635(98.4)$ & $116(95.1)$ & $751(97.9)$ \\
\hline FALSE & $10(1.6)$ & $6(4.9)$ & $16(2.1)$ \\
\hline Total & 645 & 122 & 767 \\
\hline \multicolumn{4}{|c|}{$\begin{array}{l}\text { Abuse is the recurrent nonmedical use of stimulants to } \\
\text { alter one's state of consciousness ("get high"). }\end{array}$} \\
\hline TRUE & $616(95.8)$ & $118(95.9)$ & $734(95.8)$ \\
\hline FALSE & $27(4.2)$ & $5(4.1)$ & $32(4.2)$ \\
\hline Total & 643 & 123 & 766 \\
\hline \multicolumn{4}{|c|}{$\begin{array}{l}\text { Diversion is redirection of a stimulant from its lawful } \\
\text { purpose to nonmedical or illicit use. }\end{array}$} \\
\hline TRUE & $615(95.6)$ & $117(95.1)$ & $732(95.6)$ \\
\hline FALSE & $28(4.4)$ & $6(4.9)$ & $34(4.4)$ \\
\hline Total & 643 & 123 & 766 \\
\hline
\end{tabular}




AAFP, $\mathrm{N}(\%) \quad$ ACHA, N (\%) Total, N (\%)

I prescribe after confirming that patients' complaints are consistent with ADHD symptoms via an office visit.

Not Selected

Selected

Total

I prescribe after the first evaluation without any confirmatory data.

Not Selected

Selected

Total

I wait for the evaluation report.

Not Selected

Selected

Total

I use multiple sessions to determine if treatment is necessary.

Not Selected

Selected

Total

I refer out for diagnosis.

Not Selected

Selected

Total

None of the above.

Not Selected

Selected

Total

Not applicable.

Not Selected

Selected

Total

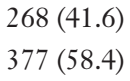

377 (58.4)

645

$$
\begin{gathered}
102(82.9) \\
21(17.1) \\
123
\end{gathered}
$$

$$
\begin{gathered}
123(100.0) \\
0(0.0) \\
123
\end{gathered}
$$

$45(5.9)$

768

$444(57.8)$

$324(42.2)$

768

$$
\begin{gathered}
492(76.3) \\
153(23.7) \\
645
\end{gathered}
$$

$$
\begin{gathered}
104(84.6) \\
19(15.4) \\
123
\end{gathered}
$$

$596(77.6)$

$$
\begin{gathered}
309(47.9) \\
336(52.1) \\
645
\end{gathered}
$$

$$
\begin{gathered}
636(98.6) \\
9(1.4) \\
645
\end{gathered}
$$
$605(93.8)$
$40(6.2)$
645

$102(82.9)$

$21(17.1)$

61 (7.9)

Appendix 9. When You Are Following a Patient for Their ADHD Medication, How Frequently Do You See Them for Follow-Up Monitoring?

\begin{tabular}{lccc}
\hline & AAFP, N (\%) & ACHA, N (\%) & Total, N (\%) \\
\hline Every month & $130(20.1)$ & $44(35.8)$ & $174(22.6)$ \\
Every 3 months & $327(50.5)$ & $30(24.4)$ & $357(46.3)$ \\
Every 6 months & $99(15.3)$ & $4(3.3)$ & $103(13.4)$ \\
Every year & $14(2.2)$ & $0(0.0)$ & $14(1.8)$ \\
When they decide to make an appointment & $1(0.2)$ & $0(0.0)$ & $1(0.1)$ \\
Never & $1(0.2)$ & $1(0.8)$ & $2(0.3)$ \\
Not applicable & $76(11.7)$ & $44(35.8)$ & $120(15.6)$ \\
Total & 648 & 123 & 771 \\
\hline
\end{tabular}


I use a state medication registry to track patient prescription drug use.

Not Selected

Selected

Total

I use random urine drug testing (UDT).

Not Selected

Selected

Total

I use urine drug testing (UDT) at every monitoring visit for a patient on ADHD medications.

Not Selected

Selected

Total

I use pill counts.

Not Selected

Selected

Total

Not applicable.

Not Selected

Selected

Total

Other.

Not Selected

Selected
$241(37.9)$

$395(62.1)$

636

$367(57.7)$

$269(42.3)$

636

$$
\begin{gathered}
603(94.8) \\
33(5.2) \\
636
\end{gathered}
$$
$518(81.4)$
118 (18.6)
636
497 (78.1)
$139(21.9)$
636

$577(90.7)$

$59(9.3)$

$$
\begin{gathered}
73(59.8) \\
49(40.2) \\
122
\end{gathered}
$$

$$
96(78.7)
$$

295 (38.9)

758

$722(95.3)$

758

122

$$
\begin{gathered}
110(90.2) \\
12(9.8) \\
122
\end{gathered}
$$

$28(82.8)$

$130(17.2)$

758

$$
\begin{gathered}
66(54.1) \\
56(45.9) \\
122
\end{gathered}
$$


Appendix 11. How Do You Evaluate Whether Your Treatment Is Working? (Please Select All That Apply)

\begin{tabular}{|c|c|c|c|}
\hline & AAFP, N (\%) & ACHA, N (\%) & Total, N (\%) \\
\hline \multicolumn{4}{|c|}{ Patient self-report. } \\
\hline Not Selected & $88(13.6)$ & $42(34.1)$ & $130(16.9)$ \\
\hline Selected & $558(86.4)$ & $81(65.9)$ & $639(83.1)$ \\
\hline Total & 646 & 123 & 769 \\
\hline \multicolumn{4}{|c|}{ Report cards for young adults. } \\
\hline Not Selected & $440(68.1)$ & $105(85.4)$ & $545(70.9)$ \\
\hline Selected & $206(31.9)$ & $18(14.6)$ & $224(29.1)$ \\
\hline Total & 646 & 123 & 769 \\
\hline \multicolumn{4}{|c|}{$\begin{array}{c}\text { Work performance } \\
\text { evaluations. }\end{array}$} \\
\hline Not Selected & $519(80.3)$ & $115(93.5)$ & $634(82.4)$ \\
\hline Selected & $127(19.7)$ & $8(6.5)$ & $135(17.6)$ \\
\hline Total & 646 & 123 & 769 \\
\hline \multicolumn{4}{|c|}{ Ask their significant other. } \\
\hline Not Selected & $395(61.1)$ & $115(93.5)$ & $510(66.3)$ \\
\hline Selected & $251(38.9)$ & $8(6.5)$ & $259(33.7)$ \\
\hline Total & 646 & 123 & 769 \\
\hline \multicolumn{4}{|c|}{ Ask their parents. } \\
\hline Not Selected & $281(43.5)$ & $115(93.5)$ & $396(51.5)$ \\
\hline Selected & $365(56.5)$ & $8(6.5)$ & $373(48.5)$ \\
\hline Total & 646 & 123 & 769 \\
\hline \multicolumn{4}{|l|}{ Not applicable. } \\
\hline Not Selected & $555(85.9)$ & $82(66.7)$ & $637(82.8)$ \\
\hline Selected & $91(14.1)$ & $41(33.3)$ & $132(17.2)$ \\
\hline Total & 646 & 123 & 769 \\
\hline \multicolumn{4}{|l|}{ Other. } \\
\hline Not Selected & $593(91.8)$ & $111(90.2)$ & 704 (91.5) \\
\hline Selected & $53(8.2)$ & $12(9.8)$ & $65(8.5)$ \\
\hline Total & 646 & 123 & 769 \\
\hline
\end{tabular}




\begin{tabular}{|c|c|c|c|}
\hline & AAFP, N (\%) & ACHA, N (\%) & Total, N (\%) \\
\hline \multicolumn{4}{|l|}{ Children (0 to 13 y.o.). } \\
\hline Monthly & $72(11.4)$ & $5(4.6)$ & $77(10.4)$ \\
\hline Every 2 to 3 months & $207(32.9)$ & $6(5.5)$ & $213(28.8)$ \\
\hline Every 3 to 6 months & $164(26.0)$ & $2(1.8)$ & $166(22.5)$ \\
\hline Every 6 to 9 months & $29(4.6)$ & $1(0.9)$ & $30(4.1)$ \\
\hline Never & $5(0.8)$ & $1(0.9)$ & $6(0.8)$ \\
\hline Not applicable & $153(24.3)$ & $94(86.2)$ & $247(33.4)$ \\
\hline Total & 630 & 109 & 739 \\
\hline \multicolumn{4}{|l|}{ Teenagers (13 to 18 y.o.). } \\
\hline Monthly & $74(11.8)$ & $19(17.1)$ & $93(12.6)$ \\
\hline Every 2 to 3 months & $201(32.0)$ & $12(10.8)$ & $213(28.8)$ \\
\hline Every 3 to 6 months & $191(30.4)$ & $6(5.4)$ & $197(26.7)$ \\
\hline Every 6 to 9 months & $42(6.7)$ & $1(0.9)$ & $43(5.8)$ \\
\hline Never & $2(0.3)$ & $1(0.9)$ & $3(0.4)$ \\
\hline Not applicable & $118(18.8)$ & $72(64.9)$ & $190(25.7)$ \\
\hline Total & 628 & 111 & 739 \\
\hline \multicolumn{4}{|c|}{ Young adult (17 to 26 y.o.). } \\
\hline Monthly & $58(9.2)$ & $35(30.2)$ & $93(12.5)$ \\
\hline Every 2 to 3 months & $205(32.5)$ & $20(17.2)$ & $225(30.2)$ \\
\hline Every 3 to 6 months & $208(33.0)$ & $15(12.9)$ & $223(29.9)$ \\
\hline Every 6 to 9 months & $66(10.5)$ & $4(3.4)$ & $70(9.4)$ \\
\hline Never & $2(0.3)$ & $1(0.9)$ & $3(0.4)$ \\
\hline Not applicable & $91(14.4)$ & $41(35.3)$ & $132(17.7)$ \\
\hline Total & 630 & 116 & 746 \\
\hline \multicolumn{4}{|l|}{ Adult (26 and older y.o.). } \\
\hline Monthly & $47(7.5)$ & $15(13.4)$ & $62(8.4)$ \\
\hline Every 2 to 3 months & $173(27.5)$ & $22(19.6)$ & $195(26.4)$ \\
\hline Every 3 to 6 months & $215(34.2)$ & $18(16.1)$ & $233(31.5)$ \\
\hline Every 6 to 9 months & $96(15.3)$ & $4(3.6)$ & $100(13.5)$ \\
\hline Never & $3(0.5)$ & $2(1.8)$ & $5(0.7)$ \\
\hline Not applicable & $94(15.0)$ & $51(45.5)$ & $145(19.6)$ \\
\hline Total & 628 & 112 & 740 \\
\hline \multicolumn{4}{|c|}{ On ADHD stimulant medication. } \\
\hline Monthly & $67(10.7)$ & $34(30.4)$ & $101(13.6)$ \\
\hline Every 2 to 3 months & $202(32.1)$ & $20(17.9)$ & $222(30.0)$ \\
\hline Every 3 to 6 months & $212(33.7)$ & $13(11.6)$ & $225(30.4)$ \\
\hline Every 6 to 9 months & $61(9.7)$ & $3(2.7)$ & $64(8.6)$ \\
\hline Never & $2(0.3)$ & $1(0.9)$ & $3(0.4)$ \\
\hline Not applicable & $85(13.5)$ & $41(36.6)$ & $126(17.0)$ \\
\hline Total & 629 & 112 & 741 \\
\hline \multicolumn{4}{|l|}{ Just initiating treatment. } \\
\hline Monthly & $424(67.5)$ & $58(52.3)$ & $482(65.2)$ \\
\hline Every 2 to 3 months & $81(12.9)$ & $3(2.7)$ & $84(11.4)$ \\
\hline Every 3 to 6 months & $21(3.3)$ & $0(0.0)$ & $21(2.8)$ \\
\hline Every 6 to 9 months & $5(0.8)$ & $2(1.8)$ & $7(0.9)$ \\
\hline Never & $2(0.3)$ & $1(0.9)$ & $3(0.4)$ \\
\hline Not applicable & $95(15.1)$ & $47(42.3)$ & $142(19.2)$ \\
\hline Total & 628 & 111 & 739 \\
\hline
\end{tabular}


AAFP, N (\%)

In their first 2 years of treatment.

Monthly
Every 2 to 3 months
Every 3 to 6 months
Every 6 to 9 months
Never
Not applicable
Total

Stable on treatment after 2 years.

Monthly

Every 2 to 3 months

Every 3 to 6 months

Every 6 to 9 months

Never

Not applicable

Total

$$
\begin{gathered}
54(8.6) \\
235(37.6) \\
215(34.4) \\
35(5.6) \\
2(0.3) \\
84(13.4) \\
625
\end{gathered}
$$
$18(2.9)$
$150(24.1)$
$227(36.4)$
141 (22.6)
$3(0.5)$
$84(13.5)$
623

ACHA, N (\%)

Total, N (\%)

$$
\begin{gathered}
23(20.7) \\
28(25.2) \\
14(12.6) \\
4(3.6) \\
2(1.8) \\
40(36.0) \\
111
\end{gathered}
$$

77 (10.5)

$263(35.7)$

$229(31.1)$

$39(5.3)$

$4(0.5)$

$124(16.8)$

736

14 (12.6)

$32(4.4)$

\begin{tabular}{|c|c|c|c|}
\hline & AAFP, N (\%) & ACHA, N (\%) & Total, N (\%) \\
\hline \multicolumn{4}{|c|}{ Misuse ADHD medication. } \\
\hline Very frequently & $21(3.3)$ & $5(4.1)$ & $26(3.4)$ \\
\hline Frequently & $111(17.3)$ & $32(26.2)$ & $143(18.7)$ \\
\hline Occasionally & $401(62.5)$ & $75(61.5)$ & $476(62.3)$ \\
\hline Rarely & $105(16.4)$ & $8(6.6)$ & $113(14.8)$ \\
\hline Never & $4(0.6)$ & $2(1.6)$ & $6(0.8)$ \\
\hline Total & 642 & 122 & 764 \\
\hline \multicolumn{4}{|c|}{ Abuse prescribed stimulants. } \\
\hline Very frequently & $17(2.6)$ & $5(4.1)$ & $22(2.9)$ \\
\hline Frequently & $93(14.5)$ & $22(18.0)$ & $115(15.0)$ \\
\hline Occasionally & $368(57.2)$ & $71(58.2)$ & $439(57.4)$ \\
\hline Rarely & $162(25.2)$ & $22(18.0)$ & $184(24.1)$ \\
\hline Never & $3(0.5)$ & $2(1.6)$ & $5(0.7)$ \\
\hline Total & 643 & 122 & 765 \\
\hline \multicolumn{4}{|c|}{$\begin{array}{l}\text { Diversion of prescribed stimulants to friends } \\
\text { or sell to other people. }\end{array}$} \\
\hline Very frequently & $21(3.3)$ & $8(6.7)$ & $29(3.8)$ \\
\hline Frequently & $86(13.4)$ & $30(25.0)$ & $116(15.3)$ \\
\hline Occasionally & $341(53.3)$ & $61(50.8)$ & $402(52.9)$ \\
\hline Rarely & $184(28.7)$ & $19(15.8)$ & $203(26.7)$ \\
\hline Never & $8(1.3)$ & $2(1.7)$ & $10(1.3)$ \\
\hline Total & 640 & 120 & 760 \\
\hline
\end{tabular}

20 (18.0)

$170(23.2)$

23 (20.7)

250 (34.1)

13 (11.7)

$154(21.0)$

$1(0.9)$

$4(0.5)$

$40(36.0)$

$124(16.9)$

111

Appendix 13. Based on Your Best Understanding, How Frequently Do Patients Engage in Any of the Following: 


\begin{tabular}{|c|c|c|c|}
\hline & AAFP, N (\%) & ACHA, N (\%) & Total, N (\%) \\
\hline \multicolumn{4}{|c|}{ Lack of knowledge about effects vs side effects. } \\
\hline Not Selected & $375(59.4)$ & $67(53.2)$ & $442(58.4)$ \\
\hline Selected & $256(40.6)$ & $59(46.8)$ & $315(41.6)$ \\
\hline Total & 631 & 126 & 757 \\
\hline \multicolumn{4}{|c|}{$\begin{array}{l}\text { Feeling the medicine isn't working } \\
\text { appropriately or losing effectiveness. }\end{array}$} \\
\hline Not Selected & $214(33.9)$ & $58(46.0)$ & $272(35.9)$ \\
\hline Selected & $417(66.1)$ & $68(54.0)$ & $485(64.1)$ \\
\hline Total & 631 & 126 & 757 \\
\hline \multicolumn{4}{|c|}{$\begin{array}{l}\text { To "get high" or because of how the medicine } \\
\text { makes them feel. }\end{array}$} \\
\hline Not Selected & $388(61.5)$ & $82(65.1)$ & $470(62.1)$ \\
\hline Selected & $243(38.5)$ & $44(34.9)$ & $287(37.9)$ \\
\hline Total & 631 & 126 & 757 \\
\hline \multicolumn{4}{|c|}{$\begin{array}{l}\text { Unintentionally not remembering the } \\
\text { recommendations. }\end{array}$} \\
\hline Not Selected & $508(80.5)$ & $101(80.2)$ & $609(80.4)$ \\
\hline Selected & $123(19.5)$ & $25(19.8)$ & $148(19.6)$ \\
\hline Total & 631 & 126 & 757 \\
\hline \multicolumn{4}{|c|}{ For performance enhancement. } \\
\hline Not Selected & $164(26.0)$ & $35(27.8)$ & $199(26.3)$ \\
\hline Selected & $467(74.0)$ & $91(72.2)$ & $558(73.7)$ \\
\hline Total & 631 & 126 & 757 \\
\hline \multicolumn{4}{|c|}{ For losing weight. } \\
\hline Not Selected & $283(44.8)$ & $72(57.1)$ & $355(46.9)$ \\
\hline Selected & $348(55.2)$ & $54(42.9)$ & $402(53.1)$ \\
\hline Total & 631 & 126 & 757 \\
\hline \multicolumn{4}{|c|}{ To pull an "all-nighter." } \\
\hline Not Selected & $288(45.6)$ & $41(32.5)$ & $329(43.5)$ \\
\hline Selected & $343(54.4)$ & $85(67.5)$ & $428(56.5)$ \\
\hline Total & 631 & 126 & 757 \\
\hline \multicolumn{4}{|c|}{ To enhance academic performance. } \\
\hline Not Selected & $270(42.8)$ & $36(28.6)$ & $306(40.4)$ \\
\hline Selected & $361(57.2)$ & $90(71.4)$ & $451(59.6)$ \\
\hline Total & 631 & 126 & 757 \\
\hline \multicolumn{4}{|l|}{ Other. } \\
\hline Not Selected & $552(87.5)$ & $113(89.7)$ & $665(87.8)$ \\
\hline Selected & $79(12.5)$ & $13(10.3)$ & $92(12.2)$ \\
\hline Total & 631 & 126 & 757 \\
\hline
\end{tabular}




\begin{tabular}{|c|c|c|c|}
\hline & AAFP, N (\%) & ACHA, N (\%) & Total, N (\%) \\
\hline \multicolumn{4}{|c|}{ History of drug use. } \\
\hline Not Selected & $123(19.2)$ & $47(37.9)$ & $170(22.2)$ \\
\hline Selected & $518(80.8)$ & $77(62.1)$ & $595(77.8)$ \\
\hline Total & 641 & 124 & 765 \\
\hline \multicolumn{4}{|l|}{ Low income. } \\
\hline Not Selected & $467(72.9)$ & $106(85.5)$ & $573(74.9)$ \\
\hline Selected & $174(27.1)$ & $18(14.5)$ & $192(25.1)$ \\
\hline Total & 641 & 124 & 765 \\
\hline \multicolumn{4}{|l|}{ Non-white race. } \\
\hline Not Selected & $472(73.6)$ & $102(82.3)$ & $574(75.0)$ \\
\hline Selected & $169(26.4)$ & $22(17.7)$ & $191(25.0)$ \\
\hline Total & 641 & 124 & 765 \\
\hline \multicolumn{4}{|c|}{ History of mental illness. } \\
\hline Not Selected & $250(39.0)$ & $77(62.1)$ & $327(42.7)$ \\
\hline Selected & $391(61.0)$ & $47(37.9)$ & $438(57.3)$ \\
\hline Total & 641 & 124 & 765 \\
\hline \multicolumn{4}{|l|}{ Male gender. } \\
\hline Not Selected & $325(50.7)$ & $68(54.8)$ & $393(51.4)$ \\
\hline Selected & $316(49.3)$ & $56(45.2)$ & $372(48.6)$ \\
\hline Total & 641 & 124 & 765 \\
\hline \multicolumn{4}{|c|}{ Affiliation with a fraternity or sorority. } \\
\hline Not Selected & $492(76.8)$ & $86(69.4)$ & $578(75.6)$ \\
\hline Selected & $149(23.2)$ & $38(30.6)$ & $187(24.4)$ \\
\hline Total & 641 & 124 & 765 \\
\hline \multicolumn{4}{|l|}{ Low GPA. } \\
\hline Not Selected & $570(88.9)$ & $101(81.5)$ & $671(87.7)$ \\
\hline Selected & $71(11.1)$ & $23(18.5)$ & $94(12.3)$ \\
\hline Total & 641 & 124 & 765 \\
\hline \multicolumn{4}{|c|}{ Competitive school or program. } \\
\hline Not Selected & $433(67.6)$ & $48(38.7)$ & $481(62.9)$ \\
\hline Selected & $208(32.4)$ & $76(61.3)$ & $284(37.1)$ \\
\hline Total & 641 & 124 & 765 \\
\hline \multicolumn{4}{|l|}{ Other. } \\
\hline Not Selected & $600(93.6)$ & $115(92.7)$ & $715(93.5)$ \\
\hline Selected & $41(6.4)$ & $9(7.3)$ & $50(6.5)$ \\
\hline Total & 641 & 124 & 765 \\
\hline
\end{tabular}


AAFP, N (\%) ACHA, N (\%) Total, N (\%)

I feel comfortable about prescribing stimulant medication.

Describes me completely

Describes me well

Describes me fairly well

Describes me somewhat

Does not describe me at all

Total

I tend to try medication even when uncertain about the diagnosis.

Describes me completely

Describes me well

Describes me fairly well

Describes me somewhat

Does not describe me at all

Total

I believe serious uncommon side effects may influence my prescribing practice.

Describes me completely

Describes me well

Describes me fairly well

Describes me somewhat

Does not describe me at all

Total

I believe treatment should be withdrawn if side effects emerge.

Describes me completely

Describes me well

Describes me fairly well

Describes me somewhat

Does not describe me at all

Total

The emergence of common side effects does not alter my treatment plan.

Describes me completely

Describes me well

Describes me fairly well

Describes me somewhat

Does not describe me at all

Total

I am not prescribing stimulant medications because I have many concerns about side effects.

Describes me completely

Describes me well

Describes me fairly well

Describes me somewhat

Does not describe me at all

Total

I always screen for depression before prescribing ADHD medication.

Describes me completely

Describes me well

Describes me fairly well

Describes me somewhat

Does not describe me at all

Total

$43(6.8)$
$164(26.1)$
$174(27.7)$
$136(21.6)$
$112(17.8)$
629

$3(0.5)$

$16(2.5)$

$40(6.4)$

$166(26.4)$

$403(64.2)$

628

$43(6.9)$
$78(12.4)$
$141(22.5)$
$219(34.9)$
$146(23.3)$
627

$88(14.1)$

$205(33.0)$

$155(24.9)$

$142(22.8)$

$32(5.1)$

622

$8(1.3)$
$50(8.0)$

143 (22.9)

185 (29.6)

$238(38.1)$

624

$\begin{array}{cc}9(7.8) & 52(7.0) \\ 19(16.5) & 183(24.6) \\ 23(20.0) & 197(26.5) \\ 17(14.8) & 153(20.6) \\ 47(40.9) & 159(21.4) \\ 115 & 744\end{array}$

$0(0.0)$

$3(0.4)$

$17(2.3)$

$42(5.6)$

$183(24.6)$

$499(67.1)$

744

$51(6.9)$

$92(12.4)$

160 (21.6)

$258(34.8)$

$181(24.4)$

742

95 (12.9)

$226(30.7)$

$184(25.0)$

$173(23.5)$

58 (7.9)

736

10 (1.4)

$61(8.3)$

167 (22.6)

$217(29.4)$

$283(38.3)$

738

\begin{tabular}{ccc}
$23(3.7)$ & $2(1.8)$ & $25(3.4)$ \\
$21(3.4)$ & $6(5.4)$ & $27(3.7)$ \\
$30(4.8)$ & $6(5.4)$ & $36(4.9)$ \\
$112(17.9)$ & $16(14.3)$ & $128(17.4)$ \\
$439(70.2)$ & $82(73.2)$ & $521(70.7)$ \\
625 & 112 & 737 \\
$128(20.6)$ & $33(29.7)$ & $161(22.0)$ \\
$196(31.5)$ & $29(26.1)$ & $225(30.7)$ \\
$148(23.8)$ & $11(9.9)$ & $159(21.7)$ \\
$85(13.7)$ & $7(6.3)$ & $92(12.6)$ \\
$65(10.5)$ & $31(27.9)$ & $96(13.1)$ \\
622 & 111 & 733 \\
\hline
\end{tabular}

Continued 
AAFP, N (\%) ACHA, N (\%) Total, N (\%)

I always screen for suicidal ideation before prescribing ADHD medication.

Describes me completely

Describes me well

Describes me fairly well

Describes me somewhat

Does not describe me at all

Total

I am not concerned with suicidal ideation or depression when prescribing

$$
\text { ADHD medication. }
$$

Describes me completely

Describes me well

Describes me fairly well

Describes me somewhat

Does not describe me at all

Total

I often conduct the reassessment via an alternative encounter (email, phone, telemedicine, remote virtual meeting, etc.)

Describes me completely

Describes me well

Describes me fairly well

Describes me somewhat

Does not describes me at all

$$
\text { Total }
$$

I believe "medication holidays" are acceptable.

Describes me completely

Describes me well

Describes me fairly well

Describes me somewhat

Does not describe me at all

$\begin{array}{ccc}145(23.4) & 35(31.3) & 180(24.7) \\ 168(27.2) & 27(24.1) & 195(26.7) \\ 139(22.5) & 12(10.7) & 151(20.7) \\ 97(15.7) & 6(5.4) & 103(14.1) \\ 68(11.0) & 32(28.6) & 100(13.7) \\ 617 & 112 & 729\end{array}$

$\begin{array}{rcc}9(1.5) & 0(0.0) & 9(1.2) \\ 22(3.6) & 3(2.7) & 25(3.4) \\ 56(9.1) & 5(4.5) & 61(8.4) \\ 94(15.2) & 7(6.3) & 101(13.8) \\ 437(70.7) & 97(86.6) & 534(73.2) \\ 618 & 112 & 730\end{array}$

$\begin{array}{ccc}12(2.0) & 5(4.5) & 17(2.3) \\ 21(3.4) & 7(6.3) & 28(3.9) \\ 35(5.7) & 4(3.6) & 39(5.4) \\ 78(12.7) & 11(9.9) & 89(12.3) \\ 469(76.3) & 84(75.7) & 553(76.2) \\ 615 & 111 & 726\end{array}$

$\begin{array}{ccc}143(23.0) & 13(11.5) & 156(21.3) \\ 208(33.5) & 23(20.4) & 231(31.5) \\ 126(20.3) & 25(22.1) & 151(20.6) \\ 92(14.8) & 20(17.7) & 112(15.3) \\ 52(8.4) & 32(28.3) & 84(11.4) \\ 621 & 113 & 734\end{array}$


You would prescribe ADHD medication for a problem patient

(e.g., patient with a history of substance abuse, mental

illness, non-compliant, etc.).

Very likely

Likely

Neither likely nor unlikely

Unlikely

Very unlikely

Total

$0(0.0)$
$18(2.9)$
$47(7.5)$
$248(39.6)$
$313(50.0)$
626

You give your patients more than a 30 day supply of their ADHD stimulant medications.

Very likely

Likely

Neither likely nor unlikely

Unlikely

Very unlikely

Total

You give refills on ADHD medications.

Very likely

Likely

Neither likely nor unlikely

Unlikely

Very unlikely

Total

If a patient is on a stimulant, you add other non-stimulant ADHD medication.

Very likely

Likely

Neither likely nor unlikely

Unlikely

Very unlikely

Total

If a patient is on a stimulant, you prescribe a second stimulant.

Very likely

Likely

Neither likely nor unlikely

Unlikely

Very unlikely

Total

If a patient is on a non-stimulant, you add a stimulant.

Very likely

Likely

Neither likely nor unlikely

Unlikely

Very unlikely

Total

If someone is misusing stimulant medication, you inquire about if they are using other substances (including alcohol).

Very likely

Likely

$$
\begin{gathered}
12(1.9) \\
87(14.0) \\
48(7.7) \\
129(20.7) \\
347(55.7) \\
623
\end{gathered}
$$
$18(3.0)$
$131(22.1)$
$54(9.1)$
$322(54.3)$
$68(11.5)$
593

$$
5(0.8)
$$

$85(13.8)$

$159(25.8)$

$181(29.3)$

$187(30.3)$

$$
617
$$

$$
0(0.0)
$$

$31(5.0)$

$143(23.2)$

$436(70.8)$

$$
616
$$

$119(19.6)$

171 (28.1)

$151(24.8)$

162 (26.6)

608

$$
\begin{gathered}
2(1.9) \\
1(0.9) \\
14(13.1) \\
32(29.9) \\
58(54.2) \\
107
\end{gathered}
$$

371 (50.6)

733

$$
\begin{gathered}
15(2.0) \\
92(12.6) \\
58(7.9) \\
148(20.2) \\
420(57.3) \\
733
\end{gathered}
$$

28 (4.1)

$139(20.2)$

68 (9.9)

$370(53.7)$

$84(12.2)$

689

$5(0.7)$

91 (12.6)

187 (26.0)

204 (28.3)

233 (32.4)

720

103

$0(0.0)$

$1(1.0)$

$0(0.0)$

7 (1.0)

$41(5.7)$

165 (22.9)

22 (21.0)

508 (70.5)

721

$7(1.0)$

130 (18.4)

$199(28.1)$

168 (23.7)

204 (28.8)

708 


\begin{tabular}{lccc}
\hline & AAFP, N (\%) & ACHA, N (\%) & Total, N (\%) \\
\hline Neither likely nor unlikely & $33(5.3)$ & $2(1.9)$ & $35(4.8)$ \\
Unlikely & $9(1.5)$ & $1(0.9)$ & $10(1.4)$ \\
Very unlikely & $22(3.6)$ & $12(11.3)$ & $34(4.7)$ \\
Total & 618 & 106 & 724 \\
You ask all adult patients with ADHD about use of other & & & \\
$\quad$ substances. & $329(52.9)$ & $58(54.2)$ & $387(53.1)$ \\
Very likely & $211(33.9)$ & $34(31.8)$ & $245(33.6)$ \\
Likely & $57(9.2)$ & $5(4.7)$ & $62(8.5)$ \\
Neither likely nor unlikely & $6(1.0)$ & $1(0.9)$ & $7(1.0)$ \\
Unlikely & $19(3.1)$ & $9(8.4)$ & $29(3.8)$ \\
Very unlikely & 622 & 107 & 729 \\
Total & & \\
\hline
\end{tabular}




\begin{tabular}{|c|c|c|c|}
\hline & AAFP, N (\%) & ACHA, N (\%) & Total, N (\%) \\
\hline \multicolumn{4}{|l|}{ Adderall. } \\
\hline $75 \%$ to $100 \%$ of the time & $31(5.1)$ & $3(1.8)$ & $33(4.6)$ \\
\hline $51 \%$ to $74 \%$ of the time & $65(10.6)$ & $14(12.4)$ & $79(10.9)$ \\
\hline $50 \%$ of the time & $57(9.3)$ & $3(2.7)$ & $60(8.3)$ \\
\hline $25 \%$ to $49 \%$ of the time & $114(18.6)$ & $24(21.2)$ & $138(19.0)$ \\
\hline Less than $25 \%$ of the time & $221(36.1)$ & $16(14.2)$ & $237(32.7)$ \\
\hline Never & $54(8.8)$ & $7(6.2)$ & $61(8.4)$ \\
\hline Not applicable & $70(11.4)$ & $47(41.6)$ & $117(16.1)$ \\
\hline Total & 612 & 113 & 725 \\
\hline \multicolumn{4}{|l|}{ Adderall XR. } \\
\hline $75 \%$ to $100 \%$ of the time & $35(5.7)$ & $3(2.5)$ & $38(5.2)$ \\
\hline $51 \%$ to $74 \%$ of the time & $62(10.1)$ & $18(15.3)$ & $80(10.9)$ \\
\hline $50 \%$ of the time & $59(9.6)$ & $9(7.6)$ & $68(8.3)$ \\
\hline $25 \%$ to $49 \%$ of the time & $148(24.1)$ & $22(18.6)$ & $170(23.2)$ \\
\hline Less than $25 \%$ of the time & $195(31.7)$ & $12(10.2)$ & $207(28.2)$ \\
\hline Never & $42(6.8)$ & $6(5.1)$ & $48(6.5)$ \\
\hline Not applicable & $74(12.0)$ & $48(40.7)$ & $122(16.6)$ \\
\hline Total & 615 & 118 & 733 \\
\hline \multicolumn{4}{|l|}{ Concerta. } \\
\hline $75 \%$ to $100 \%$ of the time & $17(2.9)$ & $1(0.9)$ & $18(2.5)$ \\
\hline $51 \%$ to $74 \%$ of the time & $32(5.4)$ & $1(0.9)$ & $33(4.6)$ \\
\hline $50 \%$ of the time & $43(7.2)$ & $3(2.6)$ & $46(6.5)$ \\
\hline $25 \%$ to $49 \%$ of the time & $91(15.3)$ & $15(13.0)$ & $106(14.9)$ \\
\hline Less than $25 \%$ of the time & $285(47.9)$ & $35(30.4)$ & $320(45.1)$ \\
\hline Never & $54(9.1)$ & $11(9.6)$ & $65(9.2)$ \\
\hline Not applicable & $73(12.3)$ & $49(42.6)$ & $122(17.2)$ \\
\hline Total & 595 & 115 & 710 \\
\hline \multicolumn{4}{|l|}{ Desoxyn. } \\
\hline $75 \%$ to $100 \%$ of the time & $0(0.0)$ & $0(0.0)$ & $0(0.0)$ \\
\hline $51 \%$ to $74 \%$ of the time & $0(0.0)$ & $0(0.0)$ & $0(0.0)$ \\
\hline $50 \%$ of the time & $3(0.5)$ & $0(0.0)$ & $3(0.4)$ \\
\hline $25 \%$ to $49 \%$ of the time & $0(0.0)$ & $0(0.0)$ & $0(0.0)$ \\
\hline Less than $25 \%$ of the time & $33(5.9)$ & $7(6.1)$ & $40(5.9)$ \\
\hline Never & $412(73.7)$ & $51(44.7)$ & $463(68.8)$ \\
\hline Not applicable & $111(19.9)$ & $56(49.1)$ & $167(24.8)$ \\
\hline Total & 559 & 114 & 673 \\
\hline \multicolumn{4}{|l|}{ Focalin XR. } \\
\hline $75 \%$ to $100 \%$ of the time & $2(0.4)$ & $0(0.0)$ & $2(0.9)$ \\
\hline $51 \%$ to $74 \%$ of the time & $7(1.2)$ & $0(0.0)$ & $7(1.0)$ \\
\hline $50 \%$ of the time & $1(0.2)$ & $0(0.0)$ & $1(0.1)$ \\
\hline $25 \%$ to $49 \%$ of the time & $15(2.7)$ & $4(3.5)$ & $19(2.8)$ \\
\hline Less than $25 \%$ of the time & $173(30.7)$ & $27(23.7)$ & $200(29.5)$ \\
\hline Never & $226(47.2)$ & $29(25.4)$ & $295(43.5)$ \\
\hline Not applicable & $100(17.7)$ & $54(47.7)$ & $154(22.7)$ \\
\hline Total & 564 & 114 & 678 \\
\hline \multicolumn{4}{|l|}{ Ritalin. } \\
\hline $75 \%$ to $100 \%$ of the time & $11(1.8)$ & $0(0.0)$ & $11(1.5)$ \\
\hline $51 \%$ to $74 \%$ of the time & $19(3.2)$ & $1(0.9)$ & $20(2.8)$ \\
\hline $50 \%$ of the time & $34(5.7)$ & $0(0.0)$ & $34(4.8)$ \\
\hline
\end{tabular}




\begin{tabular}{|c|c|c|c|}
\hline & $\mathrm{AAFP}, \mathrm{N}(\%)$ & ACHA, N (\%) & Total, N (\%) \\
\hline $25 \%$ to $49 \%$ of the time & $92(15.4)$ & $8(7.0)$ & $100(14.1)$ \\
\hline Less than $25 \%$ of the time & $265(44.4)$ & $36(31.6)$ & $301(42.3)$ \\
\hline Never & $100(16.8)$ & $18(15.8)$ & $118(16.6)$ \\
\hline Not applicable & $76(12.7)$ & $51(44.7)$ & $127(17.9)$ \\
\hline Total & 597 & 114 & 711 \\
\hline \multicolumn{4}{|l|}{ Ritalin SR. } \\
\hline $75 \%$ to $100 \%$ of the time & $7(1.2)$ & $0(0.0)$ & $7(1.0)$ \\
\hline $51 \%$ to $74 \%$ of the time & $16(2.8)$ & $0(0.0)$ & $16(2.3)$ \\
\hline $50 \%$ of the time & $26(4.5)$ & $0(0.0)$ & $26(3.8)$ \\
\hline $25 \%$ to $49 \%$ of the time & $67(11.6)$ & $5(4.5)$ & $72(10.4)$ \\
\hline Less than $25 \%$ of the time & $248(42.9)$ & $35(31.3)$ & $283(41.0)$ \\
\hline Never & $131(22.7)$ & $20(17.9)$ & $151(21.9)$ \\
\hline Not applicable & $83(14.4)$ & $52(46.4)$ & $135(19.6)$ \\
\hline Total & 578 & 112 & 690 \\
\hline \multicolumn{4}{|l|}{ Stratera. } \\
\hline $75 \%$ to $100 \%$ of the time & $10(1.7)$ & $1(0.9)$ & $11(1.5)$ \\
\hline $51 \%$ to $74 \%$ of the time & $16(2.7)$ & $0(0.0)$ & $16(2.2)$ \\
\hline $50 \%$ of the time & $22(3.7)$ & $2(1.7)$ & $24(3.4)$ \\
\hline $25 \%$ to $49 \%$ of the time & $66(11.0)$ & $9(7.8)$ & $75(10.5)$ \\
\hline Less than $25 \%$ of the time & $320(53.5)$ & $39(33.6)$ & $359(50.3)$ \\
\hline Never & $85(14.2)$ & $16(13.8)$ & $101(14.1)$ \\
\hline Not applicable & $79(13.2)$ & $49(42.2)$ & $128(17.9)$ \\
\hline Total & 598 & 116 & 714 \\
\hline \multicolumn{4}{|l|}{ Vyvanse. } \\
\hline $75 \%$ to $100 \%$ of the time & $16(2.7)$ & $2(1.7)$ & $18(2.5)$ \\
\hline $51 \%$ to $74 \%$ of the time & $22(3.6)$ & $3(2.5)$ & $25(3.5)$ \\
\hline $50 \%$ of the time & $38(6.3)$ & $5(4.2)$ & $43(6.0)$ \\
\hline $25 \%$ to $49 \%$ of the time & $81(13.4)$ & $18(15.3)$ & $99(13.7)$ \\
\hline Less than $25 \%$ of the time & $270(44.8)$ & $31(26.3)$ & $301(41.7)$ \\
\hline Never & $97(16.1)$ & $8(6.8)$ & $105(14.6)$ \\
\hline Not applicable & $79(13.1)$ & $51(43.2)$ & $130(18.0)$ \\
\hline Total & 603 & 118 & 721 \\
\hline
\end{tabular}




AAFP, N (\%) $\quad$ ACHA, N (\%) $\quad$ Total, N (\%)

Comfort with medicine.

Not Selected

Selected

Total

Previous success with same medicine.

Not Selected

Selected

Total

Patient preference.

Not Selected

Selected

Total

Organizational culture.

Not Selected

Selected

Total

Insurance coverage or coverage restrictions

Not Selected

Selected

Total

Cost.

Not Selected

Selected

Total

Preference for branded over generic.

Not Selected

Selected

Total

Preference for generic over branded.

Not Selected

Selected

Total

Evidence-based guidelines.

Not Selected

Selected

Total

Own experience.

Not Selected

Selected

Total

Preference for fast acting over slow release stimulants.

Not Selected

Selected

Total

Preference for slow release over fast acting stimulants.

Not Selected

Selected

Total

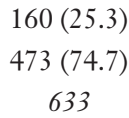

$157(24.8)$

$476(75.2)$

633

$400(63.2)$

233 (36.8)

633

$595(94.0)$

38 (6.0)

633

$172(27.2)$

$461(72.8)$

633

$236(37.3)$

397 (62.7)

633

$604(95.4)$
$29(4.6)$
633

444 (70.1)

189 (29.9)

633

432 (68.2)

201 (31.8)

633

377 (59.6)

256 (40.4)

633

$$
\begin{gathered}
574(90.7) \\
59(9.3) \\
633
\end{gathered}
$$

379 (59.9)

254 (40.1)

633

$$
\begin{gathered}
69(57.0) \\
52(43.0) \\
121
\end{gathered}
$$

$229(30.4)$

525 (69.6)

754

$$
\begin{gathered}
61(50.4) \\
60(49.6) \\
121
\end{gathered}
$$

218 (28.9)

536 (71.1)

754

$97(80.2)$

24 (19.8)

121

497 (65.9)

257 (34.1)

754

$\begin{array}{cc}114(94.2) & 709(94.0) \\ 7(5.8) & 45(6.0) \\ 121 & 754\end{array}$

70 (57.9)

242 (32.1)

$51(42.1)$

121

$512(67.9)$

754

$73(60.3)$

309 (41.0)

48 (39.7)

121

445 (59.0)

754

$116(95.9)$

$720(95.5)$

$34(4.5)$

754

121

$539(71.5)$

95 (78.5)

215 (28.5)

$26(21.5)$

754

121

509 (67.5)

77 (63.6)

$245(32.5)$

44 (36.4)

754

96 (79.3)

473 (62.7)

25 (20.7)

281 (37.3)

121

754

103 (85.1)

$677(89.8)$

18 (14.9)

77 (10.2)

121

754

78 (64.5)

457 (60.6)

43 (35.5)

297 (39.4)

121

754 


\begin{tabular}{lccc}
\hline & AAFP, N (\%) & ACHA, N (\%) & Total, N (\%) \\
\hline Not applicable. & & & \\
$\quad$ Not Selected & $573(90.5)$ & $78(64.5)$ & $651(86.3)$ \\
Selected & $60(9.5)$ & $43(35.5)$ & $103(13.7)$ \\
Total & 633 & 121 & 754 \\
Other. & $597(94.3)$ & $103(85.1)$ & $700(92.8)$ \\
Not Selected & $36(5.7)$ & $18(14.9)$ & $54(7.2)$ \\
Selected & 633 & 121 & 754 \\
Total & & & \\
\hline
\end{tabular}

Appendix 20. How Often Do You Use Any of the Following to Monitor for Possible Medication Abuse in Your ADHD Patients:

AAFP, $\mathrm{N}(\%) \quad$ ACHA, N (\%) $\quad$ Total, N (\%)

I use a state medication registry to tract patient prescription drug use.

\begin{tabular}{|c|c|c|c|}
\hline Always & $167(26.9)$ & $28(24.8)$ & $195(26.6)$ \\
\hline Very frequently & $178(28.7)$ & $19(16.8)$ & $197(26.8)$ \\
\hline Occasionally & $124(20.0)$ & $6(5.3)$ & $130(17.7)$ \\
\hline Rarely & $31(5.0)$ & $5(4.4)$ & $36(4.9)$ \\
\hline Never & $48(7.7)$ & $10(8.8)$ & $58(7.9)$ \\
\hline Not applicable & $73(11.8)$ & $45(39.8)$ & $118(16.1)$ \\
\hline Total & 621 & 113 & 734 \\
\hline \multicolumn{4}{|c|}{ use random urine drug testing (UDT). } \\
\hline Always & $76(12.3)$ & $5(4.4)$ & $81(11.1)$ \\
\hline Very frequently & $97(15.7)$ & $3(2.7)$ & $100(13.7)$ \\
\hline Occasionally & $137(22.2)$ & $19(16.8)$ & $156(21.3)$ \\
\hline Rarely & $106(17.2)$ & $11(9.7)$ & $117(16.0)$ \\
\hline Never & $133(21.5)$ & $27(23.9)$ & $160(21.9)$ \\
\hline Not applicable & $69(11.2)$ & $48(42.5)$ & $117(16.0)$ \\
\hline Total & 618 & 113 & 731 \\
\hline \multicolumn{4}{|c|}{$\begin{array}{l}\text { use urine drug testing for all patients with } \\
\text { ADHD without exceptions. }\end{array}$} \\
\hline Always & $51(8.6)$ & $9(8.2)$ & $60(8.5)$ \\
\hline Very frequently & $62(10.5)$ & $4(3.6)$ & $66(9.4)$ \\
\hline Occasionally & $69(11.6)$ & $4(3.6)$ & $73(10.4)$ \\
\hline Rarely & $87(14.7)$ & $11(10.0)$ & $98(13.9)$ \\
\hline Never & $231(39.0)$ & $32(29.1)$ & $263(37.4)$ \\
\hline Not applicable & $93(15.7)$ & $50(45.5)$ & $143(20.3)$ \\
\hline Total & 593 & 110 & 703 \\
\hline \multicolumn{4}{|c|}{ rely on patient self-reports. } \\
\hline Always & $79(13.3)$ & $18(16.1)$ & $97(13.8)$ \\
\hline Very frequently & $220(37.1)$ & $24(21.4)$ & $244(34.6)$ \\
\hline Occasionally & $107(18.0)$ & $16(14.3)$ & $123(17.4)$ \\
\hline Rarely & $60(10.1)$ & $7(6.3)$ & $67(9.5)$ \\
\hline Never & $61(10.3)$ & $8(7.1)$ & $69(9.8)$ \\
\hline Not applicable & $66(11.1)$ & $39(34.8)$ & $105(14.9)$ \\
\hline Total & 593 & 112 & 705 \\
\hline
\end{tabular}




AAFP, $\mathrm{N}(\%) \quad$ ACHA, N (\%) Total, N (\%)

I remain the primary prescriber for patients with ADHD on medication going to college.

Describes me completely

Describes me well

Describes me fairly well

Describes me somewhat

Does not describe me at all

Total

I always help/advise patients find a doctor in the college location for their ADHD medication needs.

Describes me completely

Describes me well

Describes me fairly well

Describes me somewhat

Does not describe me at all

Total

I always ask patients if they are seeing another doctor for their ADHD medications.

Describes me completely

Describes me well

Describes me fairly well

Describes me somewhat

Does not describe me at all

Total

I always ask patients about their stimulant use.

Describes me completely

Describes me well

Describes me fairly well

Describes me somewhat

Does not describe me at all

Total

I always ask about patient's use of other substances.

Describes me completely

Describes me well

Describes me fairly well

Describes me somewhat

Does not describe me at all

Total

I always discuss the stimulant diversion and misuse with my ADHD patients.

Describes me completely

Describes me well

Describes me fairly well

Describes me somewhat

Does not describe me at all

Total

I always suggest available resources and support services (behavioral therapy, counseling) to my patients with ADHD.

Describes me completely

$$
\begin{gathered}
46(7.5) \\
159(25.9) \\
150(24.4) \\
118(19.2) \\
141(23.0) \\
614
\end{gathered}
$$
$44(7.2)$
$103(16.9)$
$107(17.6)$
148 (24.3)
$206(33.9)$
608
$9(8.0)$
15 (13.3)
14 (12.4)
8 (7.1)
$67(59.3)$
113

55 (7.6)

$174(23.9)$

164 (22.6)

$126(17.3)$

208 (28.6)

727

$\begin{array}{ccc}137(22.2) & 53(45.3) & 190(25.9) \\ 196(31.8) & 31(26.5) & 227(31.0) \\ 115(18.7) & 12(10.3) & 127(17.3) \\ 85(13.8) & 7(6.0) & 92(12.6) \\ 83(13.5) & 14(12.0) & 97(13.2) \\ 616 & 117 & 733\end{array}$

149 (24.3)

$226(36.8)$

$123(20.0)$

$63(10.3)$

53 (8.6)

614

$32(27.8)$
$23(20.0)$
$19(16.5)$
$10(8.7)$
$31(27.0)$
$\quad 115$

$76(10.5)$

$126(17.4)$

$126(17.4)$

158 (21.9)

237 (32.8)

723

$202(32.6)$
$222(35.9)$
$120(19.4)$
$44(7.1)$
$31(5.0)$
619

$137(22.3)$
$168(27.3)$
$143(23.3)$
$100(16.3)$
$67(10.9)$
615

43 (36.1)

$180(24.5)$

192 (26.2)

$163(22.2)$

$112(15.3)$

87 (11.9)

734

119

$194(26.5)$ 


\begin{tabular}{lccc}
\hline & AAFP, N (\%) & ACHA, N (\%) & Total, N (\%) \\
\hline Describes m well & $188(30.7)$ & $34(28.3)$ & $222(30.3)$ \\
Describes me fairly well & $140(22.8)$ & $20(16.7)$ & $160(21.8)$ \\
Describes me somewhat & $88(14.4)$ & $5(4.2)$ & $93(12.7)$ \\
Does not describe me at all & $55(9.0)$ & $9(7.5)$ & $64(8.7)$ \\
Total & 613 & 120 & 733 \\
\hline
\end{tabular}

Appendix 22. What Do You Feel Is the Best Way to Educate Patients about ADHD (Please Select All That Apply):

\begin{tabular}{|c|c|c|c|}
\hline & AAFP, N (\%) & ACHA, N (\%) & Total, N (\%) \\
\hline \multicolumn{4}{|c|}{ Pamphlets and handouts } \\
\hline Not Selected & $327(52.1)$ & $76(61.3)$ & $403(53.6)$ \\
\hline Selected & $301(47.9)$ & $48(38.7)$ & $349(46.4)$ \\
\hline Total & 628 & 124 & 752 \\
\hline \multicolumn{4}{|c|}{$\begin{array}{l}\text { Education or counseling session at visits where prescription } \\
\text { is written. }\end{array}$} \\
\hline Not Selected & $107(17.0)$ & $15(12.1)$ & $122(16.2)$ \\
\hline Selected & $521(83.0)$ & $109(87.9)$ & $630(83.8)$ \\
\hline Total & 628 & 124 & 752 \\
\hline \multicolumn{4}{|c|}{ Give the patient links to web resources. } \\
\hline Not Selected & $335(53.3)$ & $64(51.6)$ & $399(53.1)$ \\
\hline Selected & $293(46.7)$ & $60(48.4)$ & $353(46.9)$ \\
\hline Total & 628 & 124 & 752 \\
\hline \multicolumn{4}{|c|}{ Mass media such as television and magazines. } \\
\hline Not Selected & $588(93.6)$ & $119(96.0)$ & $707(94.0)$ \\
\hline Selected & $40(6.4)$ & $5(4.0)$ & $45(6.0)$ \\
\hline Total & 628 & 124 & 752 \\
\hline \multicolumn{4}{|c|}{ Social media such as Facebook and Twitter. } \\
\hline Not Selected & $588(93.6)$ & $104(83.9)$ & $692(92.0)$ \\
\hline Selected & $40(6.4)$ & $20(16.1)$ & $60(8.0)$ \\
\hline Total & 628 & 124 & 752 \\
\hline \multicolumn{4}{|l|}{ Other. } \\
\hline Not Selected & $594(94.6)$ & $116(93.5)$ & $710(94.4)$ \\
\hline Selected & $34(5.4)$ & $8(6.5)$ & $42(5.6)$ \\
\hline Total & 628 & 124 & 752 \\
\hline \multicolumn{4}{|c|}{$\begin{array}{l}\text { Do you feel it is your responsibility to educate patients } \\
\text { with ADHD? }\end{array}$} \\
\hline No & $31(4.9)$ & $12(9.6)$ & $43(5.7)$ \\
\hline Yes & $604(95.1)$ & $113(90.4)$ & $717(94.3)$ \\
\hline Total & 635 & 125 & 760 \\
\hline
\end{tabular}


Educating about legal risks of misusing the medicine.

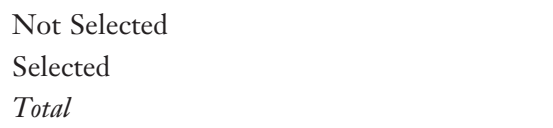

$198(32.8)$
$406(67.2)$
604

Educating about the health and physical risks of misusing the medicine.
Not Selected
Selected
Total

Educating about the mental effects of not using the medicines properly.

Not Selected

Selected

Total

Educating about how misusing medicine can affect social life and relationships such as family, job, friends and significant others.

Not Selected

$384(63.6)$
604

Total
$47(7.8)$
557 (92.2)
604
162 (26.8)
$442(73.2)$
604

$31(27.4)$

82 (72.6)

113
$13(11.5)$
$100(88.5)$
113
657 (91.6)
717

$60(8.4)$

$193(26.9)$

$524(73.1)$

717

None of the above.

Not Selected

Selected

Total

Other.

Not Selected

Selected

$591(97.8)$

13 (2.2)

604
587 (97.2)
17 (2.8)

Total

$$
\begin{gathered}
38(33.6) \\
75(66.4) \\
113
\end{gathered}
$$

258 (36.0) $459(64.0)$

$$
\begin{gathered}
109(96.5) \\
4(3.5) \\
113
\end{gathered}
$$

693 (96.7)

$24(3.3)$

717
$106(93.8)$
7 (6.2)


Appendix 24. If No to Question 32, Who Do You Feel Is Responsible (Please Select All That Apply):

\begin{tabular}{|c|c|c|c|}
\hline & AAFP, N (\%) & ACHA, N (\%) & Total, N (\%) \\
\hline \multicolumn{4}{|c|}{$\begin{array}{l}\text { Psychologist or other mental health counselor } \\
\text { who is doing any counseling in } \\
\text { conjunction with the medicine for } \\
\text { treatment. }\end{array}$} \\
\hline Not Selected & $10(31.3)$ & $3(25.0)$ & $13(29.5)$ \\
\hline Selected & $22(68.8)$ & $9(75.0)$ & $31(70.5)$ \\
\hline Total & 32 & 12 & 44 \\
\hline \multicolumn{4}{|c|}{$\begin{array}{l}\text { The other health care provider who prescribed } \\
\text { the medication in the first place. }\end{array}$} \\
\hline Not Selected & $15(46.9)$ & $4(33.3)$ & $19(43.2)$ \\
\hline Selected & $17(53.1)$ & $8(66.7)$ & $25(56.8)$ \\
\hline Total & 32 & 12 & 44 \\
\hline \multicolumn{4}{|c|}{ The patient themselves. } \\
\hline Not Selected & $23(71.9)$ & $8(66.7)$ & $31(70.5)$ \\
\hline Selected & $9(28.1)$ & $4(33.3)$ & $13(29.5)$ \\
\hline Total & 32 & 12 & 44 \\
\hline \multicolumn{4}{|c|}{ It is not anyone's responsibility. } \\
\hline Not Selected & $30(93.8)$ & $10(83.3)$ & $40(90.9)$ \\
\hline Selected & $2(6.3)$ & $2(16.7)$ & $4(9.1)$ \\
\hline Total & 32 & 12 & 44 \\
\hline \multicolumn{4}{|l|}{ Unsure. } \\
\hline Not Selected & $29(90.6)$ & $12(100.0)$ & $41(93.2)$ \\
\hline Selected & $3(9.4)$ & $0(0.0)$ & $3(6.8)$ \\
\hline Total & 32 & 12 & 44 \\
\hline \multicolumn{4}{|l|}{ Other. } \\
\hline Not Selected & $29(90.6)$ & $11(91.7)$ & $40(90.9)$ \\
\hline Selected & $3(9.4)$ & $1(8.3)$ & $4(9.1)$ \\
\hline Total & 32 & 12 & 44 \\
\hline
\end{tabular}

Appendix 25. Do You Feel it Is Your Responsibility to Prevent Misuse of ADHD Medications?

\begin{tabular}{lccc}
\hline & AAFP, N (\%) & ACHA, N (\%) & Total, N (\%) \\
\hline No & $12(6.8)$ & $0(0.0)$ & $12(5.7)$ \\
Yes & $165(93.2)$ & $32(100.0)$ & $197(94.3)$ \\
Total & 177 & 32 & 209 \\
\hline
\end{tabular}




AAFP, N (\%) $\quad$ ACHA, N (\%) $\quad$ Total, N (\%)

Evaluate each patient with suspected ADHD to confirm diagnosis before prescribing.

$104(16.5)$

Selected

Total

$525(83.5)$

629

Refer all ADHD patients to mental health professionals for care.

Not Selected

Selected

Total
$40(32.8)$

$82(67.2)$

122

$144(19.2)$

$607(80.8)$

751

$\begin{array}{cc}460(73.1) & 76(62.3) \\ 169(26.9) & 46(37.7) \\ 629 & 122\end{array}$

$536(71.4)$

$215(28.6)$

751

Educate patients with ADHD about how the stimulants should and should not be used.

Not Selected

$145(23.1)$

$484(76.9)$

629

$25(20.5)$
$97(79.5)$

122

$170(22.6)$

$581(77.4)$

751

Provide clear instructions regarding sharing and selling medications to patients with ADHD.

Not Selected

$205(32.6)$

$49(40.2)$

$254(33.8)$

$424(67.4)$

$73(59.8)$

629

122

$497(66.2)$

751

Provide specific instructions on how to dispose of any unneeded medications.

Not Selected

$379(60.3)$

$69(56.6)$

$448(59.7)$

Selected

$250(39.7)$

$53(43.4)$

629

122

$303(40.3)$

751

Strictly monitor patient's prescription medication use with urine drug tests and state registries.

Not Selected

$321(51.0)$

$87(71.3)$

$408(54.3)$

$308(49.0)$

$35(28.7)$

629

122

$343(45.7)$

751

Educate all patients of college age about misuse and risk of misusing of stimulants.

Not Selected

$211(33.5)$

$29(23.8)$

$240(32.0)$

418 (66.5)

629

93 (76.2)

122

$511(68.0)$

Total

559 (88.9)

$100(82.0)$

22 (18.0)

122

$(87.7)$

$70(11.1)$

629

$92(12.3)$

751

Other.

Not Selected

$602(95.7)$

$27(4.3)$

$116(95.1)$

$718(95.6)$

Selected

629 
Appendix 27. How Often Do You Feel Education about ADHD or ADHD Medication Should Occur?

\begin{tabular}{lccc}
\hline & AAFP, N (\%) & ACHA, N (\%) & Total, N (\%) \\
\hline Yearly & $115(18.2)$ & $11(8.9)$ & $126(16.7)$ \\
Quarterly & $109(17.2)$ & $16(13.0)$ & $125(16.6)$ \\
Every 6 months & $154(24.4)$ & $20(16.3)$ & $174(23.0)$ \\
Every time a prescription is given & $222(35.1)$ & $66(53.7)$ & $288(38.1)$ \\
Never & $1(0.2)$ & $0(0.0)$ & $1(0.1)$ \\
Other & $31(4.9)$ & $10(8.1)$ & $41(5.4)$ \\
Total & 632 & 123 & 755 \\
\hline
\end{tabular}

Appendix 28. Do You Think it's Important to Educate About the Legal Ramifications of Diversion?

\begin{tabular}{lccc}
\hline & AAFP, N (\%) & ACHA, N (\%) & Total, N (\%) \\
\hline No & $17(2.7)$ & $2(1.6)$ & $19(2.5)$ \\
Yes & $508(79.9)$ & $110(88.0)$ & $618(81.2)$ \\
Unsure & $111(17.5)$ & $13(10.4)$ & $124(16.3)$ \\
Total & 636 & 125 & 761 \\
\hline
\end{tabular}




\begin{tabular}{|c|c|c|c|}
\hline & AAFP, N (\%) & ACHA, N (\%) & Total, N (\%) \\
\hline \multicolumn{4}{|l|}{ Nature of ADHD. } \\
\hline Extremely well prepared & $57(9.0)$ & $19(15.3)$ & $76(10.0)$ \\
\hline Well prepared & $256(40.3)$ & $32(25.8)$ & $288(37.9)$ \\
\hline Somewhat prepared but can use help & $257(40.5)$ & $58(46.8)$ & $315(41.5)$ \\
\hline Unprepared and can use substantial help & $42(6.6)$ & $12(9.7)$ & $54(7.1)$ \\
\hline Not prepared at all & $23(3.6)$ & $3(2.4)$ & $26(3.4)$ \\
\hline Total & 635 & 124 & 759 \\
\hline \multicolumn{4}{|l|}{ Effects and side-effects of stimulant medications. } \\
\hline Extremely well prepared & $79(12.4)$ & $26(21.1)$ & $105(13.9)$ \\
\hline Well prepared & $312(49.1)$ & $35(28.5)$ & $347(45.8)$ \\
\hline Somewhat prepared but can use help & $205(32.3)$ & $53(43.1)$ & $258(34.0)$ \\
\hline Unprepared and can use substantial help & $23(3.6)$ & $7(5.7)$ & $30(4.0)$ \\
\hline Not prepared at all & $16(2.5)$ & $2(1.6)$ & $18(2.4)$ \\
\hline Total & 635 & 123 & 758 \\
\hline \multicolumn{4}{|l|}{$\begin{array}{l}\text { Decisions about pharmacotherapy or behavioral } \\
\text { therapy choices. }\end{array}$} \\
\hline Extremely well prepared & $46(7.3)$ & $19(15.7)$ & $65(8.7)$ \\
\hline Well prepared & $251(39.8)$ & $30(24.8)$ & $281(37.4)$ \\
\hline Somewhat prepared but can use help & $260(41.3)$ & $49(40.5)$ & $309(41.1)$ \\
\hline Unprepared and can use substantial help & $47(7.5)$ & $15(12.4)$ & $62(8.3)$ \\
\hline Not prepared at all & $26(4.1)$ & $8(6.6)$ & $34(4.5)$ \\
\hline Total & 630 & 121 & 751 \\
\hline \multicolumn{4}{|l|}{$\begin{array}{l}\text { General expectation for college life such as } \\
\text { stress, academic performance, conduct, life } \\
\text { skills and preparation strategies. }\end{array}$} \\
\hline Extremely well prepared & $71(11.4)$ & $44(35.5)$ & $115(15.4)$ \\
\hline Well prepared & $274(43.9)$ & $51(41.1)$ & $325(43.4)$ \\
\hline Somewhat prepared but can use help & $226(36.2)$ & $27(21.8)$ & $253(33.8)$ \\
\hline Unprepared and can use substantial help & $37(5.9)$ & $1(0.8)$ & $38(5.1)$ \\
\hline Not prepared at all & $16(2.6)$ & $1(0.8)$ & $17(2.3)$ \\
\hline Total & 624 & 124 & 748 \\
\hline \multicolumn{4}{|l|}{$\begin{array}{l}\text { Risky behaviors, drug abuse, medication misuse } \\
\text { and prevention strategies. }\end{array}$} \\
\hline Extremely well prepared & $63(10.0)$ & $31(25.0)$ & $94(12.6)$ \\
\hline Well prepared & $237(37.6)$ & $42(33.9)$ & $279(37.0)$ \\
\hline Somewhat prepared but can use help & $283(44.8)$ & $43(34.7)$ & $326(43.2)$ \\
\hline Unprepared and can use substantial help & $35(5.5)$ & $6(4.8)$ & $41(5.4)$ \\
\hline Not prepared at all & $13(2.1)$ & $2(1.6)$ & $15(2.0)$ \\
\hline Total & 631 & 124 & 755 \\
\hline
\end{tabular}

Appendix 30. Does Media Coverage Have the Potential to Affect Physician Views on Misuse Prevention?

\begin{tabular}{lccc}
\hline & AAFP, N (\%) & ACHA, N (\%) & Total, N (\%) \\
\hline No & $54(8.5)$ & $12(9.5)$ & $66(8.6)$ \\
Yes & $422(66.1)$ & $80(63.5)$ & $502(65.7)$ \\
Unsure & $162(25.4)$ & $34(27.0)$ & $196(25.7)$ \\
Total & 638 & 126 & 764 \\
\hline
\end{tabular}




\begin{tabular}{|c|c|c|c|}
\hline & AAFP, N (\%) & ACHA, N (\%) & Total, N (\%) \\
\hline \multicolumn{4}{|c|}{ CME/conferences. } \\
\hline Not Selected & $46(7.3)$ & $5(4.2)$ & $51(6.8)$ \\
\hline Selected & $588(92.7)$ & $114(95.8)$ & $702(93.2)$ \\
\hline Total & 634 & 119 & 753 \\
\hline \multicolumn{4}{|c|}{ Drug representative meetings. } \\
\hline Not Selected & $496(78.2)$ & $95(79.8)$ & $591(78.5)$ \\
\hline Selected & $138(21.8)$ & $24(20.2)$ & $162(21.5)$ \\
\hline Total & 634 & 119 & 753 \\
\hline \multicolumn{4}{|c|}{ Media (TV, internet). } \\
\hline Not Selected & $461(72.7)$ & $89(74.8)$ & $550(73.0)$ \\
\hline Selected & $173(27.3)$ & $30(25.2)$ & $203(27.0)$ \\
\hline Total & 634 & 119 & 753 \\
\hline \multicolumn{4}{|c|}{ Other physicians (peer groups). } \\
\hline Not Selected & $255(40.2)$ & $56(47.1)$ & $311(41.3)$ \\
\hline Selected & $379(59.8)$ & $63(52.9)$ & $442(58.7)$ \\
\hline Total & 634 & 119 & 753 \\
\hline \multicolumn{4}{|c|}{ Professional associations. } \\
\hline Not Selected & $283(44.6)$ & $46(38.7)$ & $329(43.7)$ \\
\hline Selected & $351(55.4)$ & $73(61.3)$ & $424(56.3)$ \\
\hline Total & 634 & 119 & 753 \\
\hline \multicolumn{4}{|l|}{ Journal articles. } \\
\hline Not Selected & $167(26.3)$ & $31(26.1)$ & $198(26.3)$ \\
\hline Selected & $467(73.7)$ & $88(73.9)$ & $555(73.7)$ \\
\hline Total & 634 & 119 & 753 \\
\hline \multicolumn{4}{|l|}{ Other. } \\
\hline Not Selected & $606(95.6)$ & $113(95.0)$ & $719(95.5)$ \\
\hline Selected & $28(4.4)$ & $6(5.0)$ & $34(4.5)$ \\
\hline Total & 634 & 119 & 753 \\
\hline
\end{tabular}

CME, Continuing Medical Education. 